$7-2015$

\title{
Determinants of Systemic Risk and Information Dissemination
}

Marcelo Bianconi

Xiaxin Hua

Chih Ming Tan

University of North Dakota, chihming.tan@UND.edu

How does access to this work benefit you? Let us know!

Follow this and additional works at: https://commons.und.edu/ef-fac

Part of the Economics Commons

\section{Recommended Citation}

Marcelo Bianconi, Xiaxin Hua, and Chih Ming Tan. "Determinants of Systemic Risk and Information Dissemination" (2015). Economics \& Finance Faculty Publications. 2.

https://commons.und.edu/ef-fac/2

This Article is brought to you for free and open access by the Department of Economics \& Finance at UND Scholarly Commons. It has been accepted for inclusion in Economics \& Finance Faculty Publications by an authorized administrator of UND Scholarly Commons. For more information, please contact und.commons@library.und.edu. 


\title{
Determinants of Systemic Risk and I nformation Dissemination
}

Marcelo Bianconi*
Department of Economics
Tufts University

\author{
Xiaxin Hua** \\ Department of Economics \\ Clark University
}

\author{
Chih Ming Tan*** \\ Department of Economics \\ University of North Dakota
}

\begin{abstract}
We study two measures of information dissemination on the determination of systemic risk, print-media consumer pessimism and VIX volatility. VIX volatility has a significant direct impact upon systemic risk of financial firms under distress, and consumer pessimism does impact upon firm's financial stress via the externality of other firm's financial stress. In the internet bubble of the 1990s, pessimism predicts larger systemic risk in the whole period of exuberance while the VIX predicts a sharp larger systemic risk in the height of the bubble. Our evidence suggests that consumer pessimism might be dominated by the VIX when predicting systemic risk.
\end{abstract}

Keywords: conditional value-at-risk, VIX, externality, consumer pessimism JEL Classification Codes: G00, G14.

Version, May 10, 2014

\footnotetext{
* Bianconi: Associate Professor of Economics, marcelo.bianconi@tufts.edu

** Hua: PhD student, Clark University, xhua@clark.edu

*** Tan: Professor and Page Endowed Chair in Applied Economics, chihming.tan@business.und.edu
}

We are extremely grateful to Diego Garcia for sharing his data on consumer pessimism with us and to Paul Tetlock for early initial advice on this project. We thank the comments of participants of the 2014 EEA meetings in Boston and seminar participants at the department of economics of the University of North Dakota. We also thank the research assistance of Zhe Cai. Any errors are our own. 


\section{Introduction}

The recent financial crisis of 2008 has brought about a fruitful financial economics research agenda that discriminates between systematic and systemic risk. In the latter vein, the recent contribution of Adrian and Brunnermeier (2011) has become influential in measuring the value-at-risk (VaR) of a financial system conditional on a financial institution being in some state of financial distress. ${ }^{1}$

In parallel, many researchers argue that news media plays an important role in stock market movements both theoretically and empirically. Shiller (2000) makes the conjecture that investors follow the printed word suggesting that market sentiment is driven by news' content. Empirically, Tetlock (2007) is one of the first to show that news media content can predict movements in broad indicators of stock market activity. He shows that the number of negative words in the daily "abreast of the market" column of the Wall Street Journal can predict the daily stock return from 1984 to 1999. More recently, on the same vein Garcia (2013) shows that a one standard deviation shock to a measure of market pessimism generated from the financial section of the New York Times during recessions predicts a change in the conditional average return on the Dow Jones of twelve basis points at the daily frequency from 1905 to 2005 .

This paper measures the potential effects of two alternative measures of information dissemination on the VaR of financial institution conditional on another financial institution being in some state of financial distress. A common determinant of systemic risk is the Chicago Board Options Exchange VIX, also known as the "fear" index, e.g. Adrian and Brunnermeier (2011), Chao et al (2012), Chicago Board of Exchange (CBOE, 2009). We argue here that the VIX contains information about future expectations of market volatility embodied in prices of calls and options by market participants, but this may be different from real time news data and/or the current printed word that becomes available to market participants at the time of their decision making. A key distinction in this paper is that the two forms of information dissemination presented refer to real-time printed-word information versus information about future expectations.

We use Garcia's (2013) data as a real time measure of market sentiment and the CBOE Volatility Index VIX as a measure of future expectations. Our main contribution is to use information dissemination via consumer pessimism compared to the VIX to predict extreme

\footnotetext{
1 Authors such as Chernozhukov and Umantsev (2001), Engle and Manganelli (2004), Kuan et al (2009) propose alternative measures of value-at-risk. Bisias et al (2012) and Hansen (2013) provide a broader review of the alternative approaches.
} 
risk of financial institutions in the framework of Adrian and Brunnermeier (2011). Our contribution is unique, to our knowledge, in that while others have studied average returns conditional on consumer pessimism, none have studied the tail risk of financial institutions conditional, on consumer pessimism and essentially how these risks spillover to other financial institutions.

Our sample consists of daily observations from January 2, 1992 to January 3, 2006. ${ }^{2}$ We focus on fourteen top financial institutions, namely Citigroup (CITI), American International Group Inc (AIG), Bank of America (BofA), Jefferies Group LLC (JEF), JPMorgan Chase \& Co (JPM), Morgan Stanley (MS), Goldman Sachs (GS), Raymond James Financial, Inc (RJF), Stifel Financial Corporation (SF), Wells Fargo (WF), Berkshire-Hathway (BRK), Lehman Brothers (LEH), Merrill Lynch (MLC) and Bear Stearns (BSC).

Our key result is that the print-media consumer pessimism variable, that we call pessi, has a limited direct effect on the financial stress of institutions whereas the VIX has a more significant direct effect. When the VIX is added to the state vector for the VaR estimation, the coefficients for the consumer pessimism are no longer statistically significant in most of the cases while the coefficients of the VIX are significant. However, the print-media consumer pessimism variable has a significant effect on systemic risk via the externality of stress in one institution impinged on another. This effect is identified even in the presence of similar VIX impact, thus showing that the two sources of information dissemination are distinctly identified. The time variation of the predicted $\mathrm{VaR}$ and the conditional VaR for a representative case shows that the inclusion of the consumer pessimism renders a more volatile predicted pattern and a notable reduction in financial stress after the internet bubble of the late 1990s. However, the inclusion of the VIX shows a less volatile time pattern and a sharper increase in financial stress in the late 1990s only.

Our empirical results extend the results of several papers that examine the effects of consumer pessimism of stock returns, by examining those effects from a more general information dissemination perspective on tail risk and on the externalities of tail risk of one institution into another, e.g. Da et al. (2011), Jegadeesh and Wu (2011), Kissan et al. (2011), Klubmann and Hautsch (2011), and Uhl (2011). We also extend the results of authors such as Chen et al. (2011) who compare the information dissemination impact on stock returns of print media versus social media, and Mao et al. (2011) who compare several measures of

\footnotetext{
${ }^{2}$ The sample period is where the daily data on market sentiment of Garcia (2013) overlaps with daily
} data of the VIX. 
sentiment relative to more traditional state variables. Hence, while several recent contributions focus on the effects of consumer pessimism on average returns, our key contribution is to examine these effects on tail risk. Our evidence suggests that the VIX dominates the print-media consumer pessimism as a determinant of systemic risk.

Lastly, we find that at the one and two day horizon, print-media consumer pessimism and VIX have dynamic feedback in the Granger sense, but at longer lags the VIX Granger causes the consumer pessimism measure; and in terms of volatility, we find dynamic feedback in the same day only. The VIX performs better for the in-sample and out-of-sample forecasting of conditional $\mathrm{VaR}$ and the in-sample forecast is more accurate overall for either measure, but the discrepancy between consumer pessimism and VIX accuracy is larger. In the out-of-sample case, the forecasts are less accurate for both measures overall, but the discrepancy between consumer pessimism and VIX is smaller relative to the in-sample case.

The rest of the paper is organized as follows. Section 2 presents a brief discussion of the two information measures used in the paper and a literature review. Section 3 presents the determinants of tail and systemic risk used in the empirical analysis and section 4 describes the econometric models and data. Section 5 is the core of the paper where the empirical analysis is discussed and section 6 concludes. An extended appendix presents several econometric models discussed in the text and will also be available online.

\section{Information Dissemination}

In this section, we discuss two sources of information dissemination used in this paper and provide a short review of the related literature. Information dissemination traditionally refers to a message sent out to a wide audience. ${ }^{3}$ In this paper, we interpret those messages as information that is sent out either via newspaper articles or via the observed prices of call and put options. The first is under the general rubric of market sentiment and the second is the CBOE's VIX. The key attribute is that market sentiment can be interpreted as real-time data including all information up to its instantaneous release. On the other hand, the VIX refers to current information about future expectations of market volatility. We view those as two alternative forms of information dissemination, one about messages sent via current real-time news, and the other messages regarding expectations of future potential price outcomes. Our main thesis is that those two forms of information dissemination may impact differently on

\footnotetext{
${ }^{3}$ For example, Merton (1987) is a classic paper that studies capital markets with alternative assumptions about information dissemination.
} 
systemic risk and we are set out to measure the potential differences as they impact the determination of conditional tail risk.

Relating to social media, Chen et al. (2011) use textual analysis of articles published both in the Wall Street Journal and Seeking Alpha, a popular social-media platform. They find that social-media sentiment associates strongly with contemporaneous and subsequent stock returns, even after controlling for traditional-media sentiment. Their benchmark sentiment is from "Seeking Alpha", while the "traditional-media" refers to sentiment generated from WSJ. They provide evidence that sentiment revealed through Seeking Alpha has a larger and longer-lasting impact on stock returns than views expressed in the WSJ. Our contribution is in the spirit of Chen et al. (2011), but with alternative information measures. ${ }^{4}$

\subsection{Market Sentiment}

There are several types of market sentiment data available, but for us data on sentiment generated by academic researchers from print media are our main focus. ${ }^{5}$ First and foremost, Tetlock (2007) generated an investor sentiment index from the column "Abreast of the market" of the Wall Street Journal. Each day, he used the 77 predetermined General Inquirer categories from the Harvard psychosocial dictionary to count the words in the newspaper. He then used the number of negative words to generate a measure of media content which appears to correspond to either negative investor sentiment or risk aversion. More specifically, Tetlock (2007) used a vector autoregressive model to examine the joint distribution of the Dow Jones Industrial Average returns and the market pessimism index. He found that high media pessimism predicts downward pressure on market prices followed by a mean-reversion to fundamentals, and that unusually high or low pessimism predicts higher market trading volume.

Following in those footsteps, Garcia (2013) generates a market sentiment index by analyzing the two columns of financial news of the New York Times. He constructs a measurement of market pessimism by counting the number of negative and positive words,

\footnotetext{
4 Also related to social media, Karabulut (2011) takes the Facebook Gross National Happiness (GNH) as his sentiment index and finds that GNH has the ability to predict changes both in daily returns and trading volume in the U.S. equity market. For instance, a one standard deviation increase in GNH predicts an increase in market returns equal to 11 basis points over the next day. Moreover, the impact of GNH appears to be stronger among small-cap stocks, and in the face of turmoil. Although Facebook has quite a wide cover of different investors, the happiness defined by Facebook reveals a sentiment more psychological than financial.

5 Other sentiment indexes are the University of Michigan consumer confidence index, the Thomson Reuters News Analytics engine (TRNA) index, the National Happiness Index from Facebook, Twitter investor sentiment and the CEO confidence index generated by Vistage.
} 
and then calculating "pessimism" as the number of negative words minus the number of positive words divided by total number of words (the sum of positives plus negatives). He studies the effect of sentiment on asset prices during the 20th century (1905-2005) using methodology similar to Tetlock's (2007). Garcia's (2013) main finding is that controlling for other well-known time-series patterns, the predictability of stock returns using news' content is concentrated in recessions. A one standard deviation shock to the pessimism measure during recessions predicts a change in the conditional average return on the DJIA of twelve basis points over one day. ${ }^{6}$

We use Garcia's (2013) data as our measure of real-time print-ready observations of market sentiment. Our main objective is to have a measure of market sentiment that is observed daily, based on the daily content of current news stories and that reflects information available to all on that day. Our interpretation is that this is real-time information in the sense of being measured and available instantaneously to market participants in the print media. ${ }^{7}$

\subsection{VIX}

The Chicago Board Options Exchange (CBOE) calculates the CBOE Volatility Index called VIX, also known as the "fear" index, CBOE (2009). Originally, it was designed to measure the market expectations of 30-day volatility implied by at-the-money S\&P100 index option prices. In its modern version used in this paper, the VIX is based on the S\&P500 index and estimates expected volatility by averaging the weighted prices of S\&P puts and calls options over a wide range of strike prices. The VIX is a volatility index comprised of options with the price of each option reflecting the market's expectation of future volatility of the underlying asset price. While "fear" is a form of market sentiment, the VIX contains information about future expectations of market volatility embodied in prices of calls and options by market participants. We observe that this form of information is quite different from real time print news data that becomes available instantaneously to market participants and covers current

\footnotetext{
${ }^{6}$ Compared to Tetlock's (2007) sentiment data, Garcia (2013) uses a different weighting scheme for words. While the use of the Harvard Psychological dictionary to define the mood for each word has become popular, Loughran and McDonald (2011) argue that words used to analyze financial markets sometimes have different meanings relative to their daily common use. Thus, they generate wording lists of positive and negative moods specifically for financial market analysis. Garcia (2013) uses exactly those new wording lists.

7 The market sentiment data calculated from daily newspapers stories can be analogously interpreted as a process of extracting information from real-time data. Croushore (2011) provides a recent survey of the literature in this area and another form of extracting information from real-time data is the work of Arouba, Diebold and Scotti (2009) based on dynamic factor analysis.
} 
business news stories. $^{8}$

\subsection{Related Literature Review}

In addition to the work of Tetlock (2007) and Garcia (2013), we highlight some related papers on information dissemination and processing.

Da et al. (2011) propose Google trend search frequency as the measure of investor attention. ${ }^{9}$ They show that an increase in the searching frequency predicts higher stock prices in the next two weeks and an eventual price reversal within the year. Dimpfl and Jank (2011) also use internet search queries as a proxy for retail investor's attention and find significant co-movement of stock market realized volatility and search queries for their names. More specifically, they find high searches follow high volatility, and high volatility follows high searches using Granger causality tests.

Jegadeesh and $\mathrm{Wu}$ (2011) propose another way to quantify the written word tone of 10-K filings. They uncover a significant relationship between document tone and market reaction for both negative and positive words. Their measures are significantly related to the filing period returns after controlling for factors such as returns around earnings announcements and accruals. Their evidence suggests that the market underreacts to the tone of $10-\mathrm{Ks}$, and this under-reaction is corrected over the following two weeks. Kissan et al. (2011) use online ticker searches to forecast abnormal stock returns and trading volumes. They argue that since online ticker search captures information of beliefs about cash flows and investment risks with less sophisticated retail investors, it can be a proxy for investor sentiment. In a sample of S\&P500 firms over the period 2005-2008, they find that, over a weekly horizon, online search intensity reliably predicts abnormal stock returns and trading volume. Klubmann and Hautsch (2011) use the Reuters NewsScope Sentiment Engine as their sentiment proxy, which classifies firm-specific news according to positive, neutral and negative sentiment based on linguistic pattern analysis of the respective news story. They find distinct responses in returns, volatility, trading volumes and bid-ask spreads due to news' arrivals. They show that a classification of news according to indicated relevance is crucial to filter out noise and to identify significant effects. Moreover, sentiment indicators have

\footnotetext{
${ }^{8}$ Of course, VIX market participants also read the current, real time news and hence we expect that the two measures present some degree of correlation. Recently, Bloom (2014) discusses the countercyclical aspects of the VIX.

9 The Google search engine is a form of real time data source associated with the nowcasting approach to forecasting. See e.g. Varian and Choi (2009) on nowcasting with Google search engines and Giannone, Reichlin, and Small (2008) for nowcasting in macroeconomics using dynamic factor analysis.
} 
predictability for future price trends even though the profitability of news-implied trading is deteriorated by increased bid-ask spreads. Uhl (2011) also uses the Reuters news articles sentiment, and find significant effect on the Dow Jones Industrials Index. The paper shows that sentiment can explain and predict changes in stock returns better than macroeconomic factors. Moreover, they find that negative sentiment performs better in simple trading strategies to predict stock returns than positive sentiment, while the sentiment effect remains* over months.

Since there are several kinds of consumer sentiment emerging in recent years, Mao et al. (2011) try to compare the effectiveness of different sentiments. They survey a range of online data sets like Twitter feeds, news headlines, and volumes of Google search queries and sentiment tracking methods like Twitter Investor Sentiment, Negative News Sentiment and Tweet \& Google Search volumes of financial terms, and compare their value for financial prediction of market indices such as the Dow Jones Industrial Average, trading volumes, and market volatility measured by the VIX, as well as gold prices. They also compare the predictive power of traditional investor sentiment survey data, i.e. Investor Intelligence and Daily Sentiment Index, against those of the mentioned set of online sentiment indicators. Their results show that traditional surveys of Investor Intelligence are lagging indicators of the financial markets. However, weekly Google Insight Search (GIS) volumes on financial search queries do have predictive value. An indicator of Twitter Investor Sentiment and the frequency of occurrence of financial terms on Twitter in the previous 1-2 days are also found to be very statistically significant predictors of daily market log return. Survey sentiment indicators are however found not to be statistically significant predictors of financial market values, once they control for all other mood indicators as well as the VIX.

There is a vibrant literature exploring the effects of consumer sentiment on stock markets. However, most of the studies mainly discuss the relation between consumer sentiment and stock returns or prices. None, to our knowledge, use consumer sentiment to predict the extreme risk of stock market. This is our main contribution, to use information dissemination via consumer sentiment and compare it to the information dissemination of the VIX as determinants of extreme risk of financial institutions.

\section{Determinants of Systemic Risk}

Our approach for systemic risk is the tail measure of systemic risk proposed by Adrian and 
Brunnemeier (2011). ${ }^{10}$ This approach measures co-dependence between tails of equity returns and financial institutions. Some form of co-dependence is needed to distinguish the impact of the disturbances to the entire financial sector from the firm-specific disturbances in this case. Since our main objective is to evaluate the effects of two forms of information dissemination on systemic risk, the conditional value at risk (CoVar) approach fits well with our purposes.

\subsection{Value-at-Risk (VaR)}

A Value-at-Risk model gives the maximum loss that can be expected, at a particular significance level, over a given trading horizon. It is the $\tau$-quantile of the return distribution at time $\mathrm{t}+\mathrm{d}$ conditioned on the information $\operatorname{set} F_{t}$ :

$$
\operatorname{VaR}_{t+d}^{\tau} \stackrel{\text { def }}{=} \inf \left\{x: P\left(X_{t+d} \leq x \mid F_{t}\right) \geq \tau\right\}
$$

where $X_{t}$ denotes an asset return and $\tau$ is taking values such as $0.05,0.01$ or 0.001 to reflect the negative extreme risk. In order to predict $\mathrm{VaR}$, one can use quantile regression, e.g. Koenker and Basset (1978). In general, models based in (1) mainly focus on the VaR for individual assets and do not directly take into account the potential spillover effects that characterize interactions during periods of stress. ${ }^{11}$

\subsection{Conditional Value-at-Risk (CoVaR)}

Adrian and Brunnermeier (2011) propose the CoVaR concept. Specifically, let $C\left(X_{i, t}\right)$ represents some event function of the return of asset $i, X_{i, t}$ at time t, and let $X_{j, t}$ be the return of another asset. $\operatorname{CoVaR}_{j \mid i, t}^{\tau}\left(X_{i, t}\right)$ is defined as the $\tau$-quantile of the conditional probability distribution:

$$
P\left\{X_{j, t} \leq \operatorname{CoVaR} R_{j \mid i, t}^{\tau} \mid C\left(X_{i, t}\right), M_{t}\right\}=\tau
$$

Where $M_{t}$ is a vector of state variables potentially including information dissemination variables. The standard CoVaR approach is to set $C\left(X_{i, t}\right)=\left\{X_{i, t}=\operatorname{VaR} R_{X i, t}^{\tau}\right\}$.

\footnotetext{
${ }^{10}$ Bisias et al. (2012) have summarized and identified at least thirty potential measures of systemic risk. While Hansen (2013) points out that there is not a single unified approach for the measurement of systemic risk, besides the tail risk used in this paper, he summarizes other three specific useful approaches: Contingent claims analysis of Gray and Jobst (2011), who feature risk adjustments to sectoral balance sheets while paying special attention to the distinct role of debt and equity; Dynamic, stochastic macroeconomic models discussed by Gertler and Kiyotaki (2010) and Network models in its infancy.

11 Engle and Manganelli (2004) propose the nonlinear Conditional Autoregressive Value at Risk(CaVaR) model, in which they use lagged VaRs and lagged returns. Chernozhukov and Umantsev (2001) propose linear and quadratic time series models for VaR prediction. Kuan et al.(2009) propose the Conditional Auto Regressive Expectile model and argue that expectiles are more sensitive to the scale of losses.
} 


\section{Empirical Methodology and Data}

\subsection{Model settings}

For our benchmark model setting, we follow Adrian and Brunnermeier's (2011) CoVaR framework. In the first step, we predict the 5\% value at risk (VaR) of an individual asset return $X_{i, t}$ at the daily horizon using a linear quantile regression model on the market state variables:

$$
X_{i, t}=\alpha_{i}+\pi_{1 i} I D_{t, t-1}+\gamma_{i}^{T} M_{t-1}+\varepsilon_{i, t}
$$

where $\gamma_{i}^{T}$ means the transpose of $\gamma_{i}, I D_{t, t-1}$ is one or both information variables considered (sentiment or vix), and $M_{t}$ is a vector of the state variables. ${ }^{12}$ This model is estimated with quantile regression to obtain the coefficients $\left(\widehat{\alpha_{i}}, \widehat{\pi_{1 i}}, \widehat{\gamma_{i}^{T}}\right)$ with $F_{\varepsilon i, t}^{-1}\left(\tau \mid M_{t-1}\right)=0$. The VaR of asset $i$ is predicted by

$$
\widehat{V a R_{l, t}}=\widehat{\alpha_{\imath}}+\widehat{\pi_{1 l}} I D_{t, t-1}+\widehat{\gamma_{l}^{T}} M_{t-1} .
$$

The second step is to model the externality of asset $i$ on asset $j$. Thus, the rate of return of asset $\mathrm{j}$ is taken to be a linear function of asset's $\mathrm{i}$ return, and this external effect can be sensitive to the information variable both directly and through the return of asset $i$, and state variables M. Hence, the specification is

$$
X_{j, t}=\alpha_{j \mid i}+\pi_{1 j \mid i} I D_{t, t-1}+\pi_{2 j \mid i}\left(I D_{t, t-1} \times X_{i, t}\right)+\beta_{j \mid i} X_{i, t}+\gamma_{j \mid i}^{T} M_{t-1}+\varepsilon_{j, t} .
$$

where we again employ quantile regression and obtain coefficients $\left(\widehat{\alpha_{j \mid i},}, \widehat{\pi_{1 j \mid i}}, \widehat{\pi_{2 j \mid i},}, \widehat{\beta_{j \mid i}}, \widehat{\gamma_{i}^{T}}\right)$. Then, the CoVaR is calculated as:

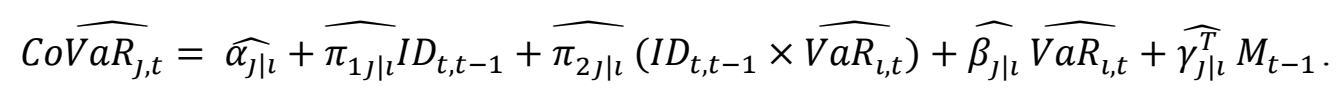

In summary, expression (5) reflects the externality of the stress of institution $i$ on the stress of institution $\mathrm{j} .{ }^{13}$ Our information measures not only affect the stress of institution $\mathrm{j}$ directly but also influence the externality of institution i via the interaction term and similar rationale applies to the CoVaR expression (6).

\subsection{Data}

Our sample consists of daily observations from January 2nd 1992 to January 3rd 2006. Our sample include the top investment banks in the U.S. plus America International Group (AIG) and Berkshire-Hathway (BRK) which are key market participants in credit default swaps and other derivative financial instruments. The institutions are Citigroup (CITI), American

\footnotetext{
12 Quantile regressions are discussed in Koenker and Bassett (1978). Adrian and Brunnermeier (2011) have a set of seven basic state variables. We explain our state vector below.

13 Brunnermeier (2009) describes several channels of externalities among financial institutions including fire-sale externality, hoarding externality, bank runs externality and network externality.
} 
International Group Inc (AIG), Bank of America (BofA), Jefferies Group LLC (JEF), JPMorgan Chase \& Co (JPM), Morgan Stanley (MS), Goldman Sachs (GS), Raymond James Financial, Inc (RJF), Stifel Financial Corporation (SF), Wells Fargo (WF) Berkshire-Hathway (BRK), Lehman Brother (LEH), Merrill Lynch (MLC) and Bear Stearns (BSC). For each, we have daily stock returns, $X_{i \text { or } j}$.

Our state vector may include the information dissemination variables which are the consumer pessimism index from Garcia (2013) and the CBOE VIX index. The consumer pessimism generated by Garcia (2013) is from the New York Times financial section given by market pessimism $=\frac{\text { Number of negative words-Number of positive words }}{\text { Total number of words }}$.

where we use pessi for short. Thus the higher (lower) the value of Consumer pessimism index, the more (less) pessimistic the market is. The historical data for the VIX can be found on the Chicago Board Options Exchange's website.

The other set of state variables in reference to $M_{t-1}$ in expressions (3)-(5), are the remaining six variables used by Adrian and Brunnermeier (2011), respectively:

a. Short term liquidity spread: Measuring short-term liquidity risk by the difference between the three-month treasury repo rate and the three-month treasury bill rate. The repo data is from the Bloomberg database and the treasury bill rate data is from the Federal Reserve Board H.15.

b. The daily change in the three-month treasury bill rate: Adrian and Brunnermeier find that the changes have better explanatory power than the levels for the negative tail behavior of asset returns.

c. The change in the slope of the yield curve: The slope is defined by the difference of the ten-year treasury rate from the three-month treasury bill rate.

d. The change in the credit spread between 10 years BAA-rated bonds and the 10 years treasury rate.

e. The daily Dow Jones U.S. Real Estate index returns: The index reflects the information of lease rates, vacancies, property development and transactions of real estates in the U.S.

f. The daily S\&P500 index returns: An approximate of the theoretical market portfolio returns.

The variables c., d., e. are from the Federal Reserve Board H.15 and the data of e. and f. are from Yahoo Finance. ${ }^{14}$

\footnotetext{
${ }^{14}$ In both Adrian and Brunnermeier (2011) as well as Chao et al.(2012) semi-parametric approach, the VIX is also used as a state variable, a proxy of market fear. Since we consider the measure of consumer 
Table 1 presents the summary of our data set. The total sample is from January 2, 1992 to January 3, 2006 while the sample for the return of Morgan Stanley (MS) is from February 23, 1993 to January 3, 2006, the sample for the return of Goldman Sachs (GS) is from May 5, 1999 to January 3, 2006, the sample for the return of Berkshire-Hathway(BRK) is from May 10, 1996 to January 3, 2006 and the sample of Lehman Brother(LEH) is from May 3, 1994 to January 3, 2006, since the stocks of Goldman Sachs, Berkshire-Hathway and Lehman Brother(LEH) went public later than January 2, $1992 .{ }^{15}$ We define the daily stock return of all fourteen institutions as well as the S\&P500 index and the Dow Jones US Real Estate index returns as the business day difference of the logarithm of the adjusted close prices. The VIX remains as the original data from the Chicago Board Options Exchange's website. The Consumer pessimism is the market pessimism of Garcia (2013) as explained above. We can highlight in Table 1 that the maximum value of the Consumer pessimism is 0.066 , the minimum value of it is -0.019 and the average of the total sample is 0.013 . As mentioned the higher the value of Consumer pessimism, the more pessimistic the market is and our sample is biased on average towards more pessimistic days.

\section{Systemic Risk and Information Dissemination}

\subsection{Consumer pessimism}

In this set of regressions, we include the current consumer pessimism measure, pessi, in the VaR and CoVaR estimations, but do not include the VIX in the state vector.

The first set of regressions estimated is the quantile regression equation (3) to obtain the VaR of each institution. In our quantile regressions, $\tau$ always takes the value of $0.05(5 \%)$. Next, we generate the predicted VaR of each institution as defined in equation (4) and run the quantile regression defined in equation (5) to get the coefficients to predict CoVaR for each institution as well as to capture the systemic risk across different institutions.

\footnotetext{
sentiment of Garcia (2013) as real time data, we use its value as of the current period, $t$, while the VIX as used in the authors above is part of the state variables at $t-1$.

15 While Morgan Stanley first went public in 1986, its data starts on Feb 23, 1993. The issue is the following. In 1997, Morgan Stanley merged with a financial services company called Dean Witter, Discover \& Co and the new company at the time was named Morgan Stanley, Dean Witter, Discover \& Co. At the time, each share of Morgan Stanley stock was converted into 1.65 shares of Dean Witter stock. However, Dean Witter, Discover \&Co., a spinoff from Sears, first went public on February 22, 1993 starting trading on February 23, 1993. Since in 1997, Morgan Stanley stock was converted into Dean Witter, the new company at the time MS, DW, D \& Co just goes back to when Dean Witter was first made public, not when Morgan Stanley was made public in 1986.
} 
Tables 2 show the CoVaR regression results for CITI, AIG and BofA. ${ }^{16}$ Columns (1-13) present the stress external effect of the thirteen other institutions on Citigroup including the effects of the consumer pessimism pessi directly and through the externality. The direct effect of pessi is negligible and not statistically significant in all except for two cases. However, the effect of pessi through the externality of other institutions on CITI is positive and statistically significant in more than half of the cases. In the cases of American International Group, Columns (14-26), the direct effect of pessi is negative and statistically significant in seven cases and the effect through the externality is positive and significant in eight cases. The qualitative direct effect implies that an increase in consumer pessimism decreases the already negative VaR making the potential losses higher. However, when interacted with the external effect of financial stress of other institutions, the impact of financial stress of the other institution on the stress of AIG is larger in magnitude due to the consumer pessimism effect.

Columns (27-39) show that for Bank of America the direct effect of pessi is statistically significant in six cases, and significant in five cases via externality. For all other companies j, tables are in the appendix. For JEF, there is almost no direct effect, but there are five significant cases via the externality. In the cases of JPMorgan, Morgan Stanley, Lehman Brother, Merrill Lynch and Bear Stearns, there are both negative statistically significant direct effect of pessi and positive effect via externality. The cases of Goldman Sachs, Stifel Financial and Berkshire-Hathway show negligible direct and indirectly via externality effects while Raymond James Financial and Wells Fargo show no direct effects, but several effects via externality.

Figure 1.1 shows the summary of all CoVaR estimations in terms of the external effects of institution $\mathrm{i}$ on institution $\mathrm{j}$ via the pessi variable, as a directed network. ${ }^{17}$ Institutions like Goldman Sachs, Stifle Financial and Berkshire-Hathway are seen with very few directed arrows indicating low impact of the consumer pessimism via externality for those institutions. Bank of America, Jefferies Group Raymond James Financial Bear Stearns and Wells Fargo have a little bit more external stress impact through consumer pessimism. Other institutions like Morgan Stanley, Merrill Lynch, JPMorgan, AIG, Lehman Brother and

\footnotetext{
${ }^{16}$ All regressions of the VaR estimations from equation (3) are available upon request. Tables 2 present results for three companies, the remaining regressions for the other seven companies are discussed but available in an online appendix.

17 Acemoglu et al. (2013) studies the network foundations of systemic risk; see also the survey of Hansen (2013).
} 
CITI are much more impacted by consumer pessimism via externalities.

Figure 1.2 row(1) shows cases of the CoVaR and VaR prediction sequence for each Citigroup when JPMorgan is under financial stress; and in the case of JPMorgan, when Citigroup is under financial stress. ${ }^{18}$ For all 14 institutions, the CoVaR forecasts (red) seem to be closer to the average bottom 5\% returns (green) as compared to the VaR forecasts (blue). The reason for this difference is that the CoVaR captures the additional external effect of systemic risk. However, one can also notice that even the CoVaR forecasts deviate significantly from the bottom 5\% returns average line. The graph for GS in the sample 1999-2006 shows the norm for all companies that the predicted VaR and CoVaR have higher absolute value in the mid to late 1990s in the period of what Shiller (2000) coined as irrational exuberance. Mostly after 2001, both VaR and CoVaR decrease in absolute value coinciding with the end of the internet bubble.

\subsection{VIX}

While consumer pessimism (pessi) represents one form of information dissemination, the VIX aggregates an alternative form of information dissemination, information about future expectations. Both Adrian and Brunnermeier (2011) as well as Chao et al (2012) include the VIX as a state variable.

Table 3 shows the CoVaR regression results with the VIX for the three companies CITI, AIG and BofA. Column(1) Column(13) present the stress external effect of the fourteen other institutions on CITI including the effects of the VIX directly and through the externality. In contrast to the consumer pessimism case, the direct effect of the VIX statistically significant and negative in all cases; and the effect of VIX through the externality of other institutions on CITI is positive and statistically significant in most cases. The qualitative direct effect implies that an increase in VIX decreases the already negative VaR making the potential losses higher. However, when interacted with the external effect of financial stress of other institutions, the impact of financial stress of the other institution on the stress of CITI is larger in magnitude due to the VIX effect when both coefficients for the other institutions and VIX are statistically significant.

In the case of AIG, Columns (14-26), the direct effect of VIX is negative and statistically significant in all cases and the effect through the externality is positive and

\footnotetext{
18 There are 182 figures of sequences in total; we present one sequence as representative of the time varying VaR and CoVaR; and similarly for Figures 2.2 and 3.2. Figure2 presents the sequences of two cases, the remaining regressions for the other 180 figures are discussed but are partially available in an online appendix.
} 
significant in seven cases. Columns (27-39) show that for BOA the direct effect of the VIX is statistically significant in all cases, and significant in seven cases via externality. For other regressions available in the appendix, in the case of JEF, there is only three significant cases of direct effect but six cases via the externality. In the cases of JP, MS, BRK, LEM, MLC and BSC there are both negative statistically significant direct effects of VIX and positive effect via externality. The case of GS has negative and statistically significant direct effect of VIX in all cases (in contrast to the pessi case), and six cases via externality. RFJ and WF show all significant direct effects and almost all significant effects via externality. SF is quite different than the other institutions in relation to the impact of VIX. There are very few significant direct effects, but they are all positive and the effect through the externality is not significant at all.

Figure 2.1 shows the summary of all CoVaR regressions in terms of the external effects of institution $\mathrm{i}$ on institution $\mathrm{j}$ via the VIX variable, as a directed network. All institutions are impacted by VIX via externalities with the stark exception of SF.

Figure 1.2 row (2) shows the CoVaR and VaR prediction sequence of CITI when JP is under financial stress; and in the case of JP when CITI is under financial stress. Similarly to the case of the consumer pessimism, the CoVaR forecasts (red) are closer to the average bottom 5\% returns (green) when compared to the VaR forecasts (blue) because of the additional external effect of systemic risk and via the VIX. Relative to the consumer pessimism case above, the predicted VaR and CoVaR is notably less volatile across the time sample and the pattern is one of a sharper decline late in 1999 relative to the mid-1990s and after 2001. This evidence points to the potential more prominent impact of print-media consumer pessimism in the period of exuberance of the mid to late 1990s as a determinant of firm's higher financial stress.

\subsection{Consumer pessimism versus VIX}

An important thesis of this paper is that the two forms of information dissemination proposed refer to real-time instantaneous information versus information about future expectations. What are the results when we include both consumer pessimism and VIX in the VaR and the CoVaR estimations?

Tables 4 show the CoVaR regression results for the selected companies CITI, AIG and BOA. The tables, including the ones in the appendix, show the stark contrast of the direct effect of the two information variables on the financial stress of institutions. The VIX has a negative and statistically significant effect in all but one case of institution CITI; while in only three cases the consumer pessimism have significant direct impact. However, through 
the externality of other institutions, both the VIX and the consumer pessimism have significant and separately identified effects in most of the cases.

Figure $3.1(a, b)$ shows the summary of all CoVar regressions in terms of the effects of institution $\mathrm{i}$ on institution $\mathrm{j}$ via the pessi and the VIX variables as a directed network. The direct external effects of the information variables are more intense in the case of the VIX, but the consumer pessimism impacts significantly in many cases, showing the key relevance of the external effects of other institutions in the determination of tail risk and in the potential identification of informational effects.

Figure 3.2 shows he CoVaR and VaR prediction sequence for part of the institutions when both the consumer pessimism and the VIX are included, and when JPMorgan is under financial stress; and in the case of JPMorgan when CITI is under financial stress for each institution. Similarly, the CoVaR forecasts (red) are closer to the average bottom 5\% returns (green) when compared to the VaR forecasts (blue) because of the additional external effect of systemic risk and via consumer pessimism and VIX. The time variation is slightly more similar to the VIX only case in the sense that the predicted VaR and CoVaR is slightly less volatile across the time sample and the pattern is one of a sharper decline late in 1999 relative to the mid-1990s and after 2001.

\subsubsection{Consumer pessimism versus VIX: Granger Causality and Volatility Causality}

The instantaneous correlation between consumer pessimism and (lagged) VIX is positive, statistically significant and of an order of magnitude of $21.7 \%$. We believe this is not enough to make collinearity a main culprit for the results above. Figure 4 shows the daily sequence of VIX and consumer pessimism. We found that VIX moves less vibrantly than pessi in the short run while in the long run, pessi remains more constant. In this section we ask the following question: Do consumer pessimism measured by pessimism and the VIX have any causal relationship, both in the Granger sense of their conditional expectation, and/or in the sense of their volatility?

First, we examined the sample cross-correlation function between consumer pessimism and VIX. The correlations are all positive so that both series co-move in the same direction. A peak correlation is where the VIX leads the consumer pessimism by one day. ${ }^{19}$ Then, we perform Granger causality tests between the two variables at alternative lags. Table 5 shows Granger causality tests between consumer pessimism and VIX. In the very short horizon of one and two days, there is some evidence of causality in both directions

${ }^{19}$ This is available at the accompanying website to be completed. 
(dynamic feedback) even though causality from the VIX to consumer pessimism is stronger. After the two day horizon, there is no evidence of feedback from consumer pessimism to VIX and the VIX Granger causes the consumer pessimism in a unidirectional manner.

We perform similar analysis using a measure of volatility of the consumer pessimism and the VIX given by the predicted standardized squared residuals of an ARCH(1)-GARCH(1) model fit for each variable separately. Most of the correlations between volatilities are not significant, but the red line shows a peak correlation where the VIX volatility leads the consumer pessimism volatility by 13 days.

We then test variance causality between the two series using the method proposed by Cheung and $\mathrm{Ng}$ (1996). Table 6 shows variance causality tests between consumer pessimism and VIX at alternative lags according to the CCF statistic of Cheung and $\mathrm{Ng}$ (1996). The values are based on the cross correlation function estimated from the squared standardized residuals of the $\mathrm{ARCH}(1)-\mathrm{GARCH}(1)$ models for each variable shown in Figure 5. The test is performed for each lag using the chi-square distribution with 1 degree of freedom at a 5\% significance level (3.8414). The reported results are the statistically significant ones. We find significant causality in variance from the VIX to the consumer pessimism at lag 13 (13 days) and from the consumer pessimism to the VIX at lag 6 (6 days). There is significant simultaneous causality in variance at lag 0 , in the same day.

Hence, we find that in the very short term, one or two days, consumer pessimism and VIX have dynamic feedback, but at longer lags the VIX Granger causes the consumer pessimism measure. This is not surprising since the VIX is a more explicit forward looking measure. In terms of volatility, we also find dynamic feedback in the same day, but very little significant causality in both directions at longer lags.

\subsubsection{Consumer pessimism versus VIX: In-Sample and Out-of-Sample Predictions}

In this section, we compute in-sample and out-of-sample predictions of the estimated CoVaR with the two alternative sources of information dissemination separately and compare their accuracy. The remaining state variables are the same and the only difference is the information variable. The loss function for the forecasting accuracy is defined as the squared difference between the predicted 5\% CoVaR and the actual 5\% quantile of the return of the financial institution in question.

In the in-sample case, the VIX performs better in 170 out of the 182 cases, while the consumer pessimism performs better in only 12 cases, 6 being for the case of JEF. The VIX works much better when capturing the extreme returns in the two step system of quantile regressions. The top ranked pairs are (JEF, WF); (GS, BRK), (BSC, JP), (GS, BofA) and 
(CITI, WF) which have a discrepancy in performance of less than $2 \%$ and for those pairs the systemic risk prediction is not sensitive to the type of information being considered. The Berkshire-Hathaway (BRK) shows in the top 5 ranked for the largest discrepancy. The next lower ranked pairs are (SF, GS), (GS, SF), (BRK, GS), (BRK, BSC), (AIG, SF), (BRK, AIG), (RJF, SF), (LEH, SF) which have the discrepancy with the performance of consumer pessimism worst $500 \%$ or above that of VIX. For those pairs, the VIX provides a much superior systemic risk prediction than consumer pessimism, in particular for Berkshire-Hathaway.

In the out-of-sample case, the VIX performs better in 178 out of the 182 cases, while the consumer pessimism performs better in only 4 cases and the VIX works better for the out-of-sample as well. First, for SF pessimism works better in all 4 cases. The top ranked pairs are (SF, JP), (SF, BRK), (SF, GS) and (SF, BSC) which have a discrepancy in performance of less than $2 \%$ and for those pairs the systemic risk prediction is not sensitive to the type of information being considered. The lower ranked pairs are (BSC, BRK); (JP, BRK), (CITI, BRK) and (JP, GS) which have the largest discrepancy with the performance of consumer pessimism worst $300 \%$ or above that of VIX. For those pairs, the VIX provides a superior systemic risk prediction than consumer pessimism.

Hence, the in-sample is more accurate overall for either measure, but the discrepancy between consumer pessimism and VIX accuracy is larger. In the out-of-sample case, the forecasts are less accurate for both measures overall, but the discrepancy between consumer pessimism and VIX is smaller relative to the in-sample case.

\subsubsection{Consumer pessimism versus VIX: Summary}

Our evidence points to several key remarks. First, the direct effect of the print-media consumer pessimism variable on the financial stress of institutions is limited whereas the VIX has a more significant direct effect. When the VIX is added to the state vector for the VaR estimation, the coefficients for the consumer pessimism are no longer statistically significant in most of the cases while the coefficients of the VIX are significant. However, the print-media consumer pessimism variable has a significant effect on systemic risk via the externality of stress in one institution impinged on another. This effect is identified even in the presence of similar VIX impact, thus showing that the two sources of information dissemination are distinct.

Second, the time variation of the predicted VaR and CoVaR for a representative case shows that the inclusion of the consumer pessimism renders a more volatile predicted pattern and a notable reduction in financial stress after the internet bubble of the late 1990s. However, 
the inclusion of the VIX shows a less volatile time pattern and a more sharp increase in financial stress in the late 1990s only.

Third, at the one or two day horizon, print-media consumer pessimism and VIX have dynamic feedback in Granger sense, but at longer lags the VIX Granger causes the consumer pessimism measure; and in terms of volatility, we find dynamic feedback in the same day only. The VIX performs better for the in-sample and out-of-sample forecasting of CoVaR and the in-sample forecast is more accurate overall for either measure, but the discrepancy between consumer pessimism and VIX accuracy is larger. In the out-of-sample case, the forecasts are less accurate for both measures overall, but the discrepancy between consumer pessimism and VIX is smaller relative to the in-sample case.

\section{Summary and Conclusion}

We examine the effect of information that is sent out either via newspaper articles or via the observed prices of call and put options on the tail risk and systemic risk of ten top large financial services institutions. We use Garcia's (2013) data as a measure of market sentiment and the CBOE Volatility Index VIX.

The two forms of information dissemination proposed have potentially distinct and identifiable effects on systemic risk. The print media consumer pessimism impacts financial stress through the externality of other firm's financial stress while the VIX has a direct effect and through the externality. In the mid to late 1990s period of exuberance, given the internet bubble, the consumer pessimism predicted a higher financial stress while the VIX predicted a sharp temporary increase in financial stress close to the burst of the bubble in 1999.

We find that in the very short term, one or two days, consumer pessimism and VIX have dynamic feedback, but at longer lags the VIX Granger causes the consumer pessimism measure. In terms of volatility, we also find dynamic feedback in the same day, but very little significant causality in both directions at longer lags. This piece of evidence confirms our suspicion that market participants that engage into trades with call and put options also read the real time news that form the basis for the consumer pessimism real time data.

Our in-sample versus out-of-sample forecasts show that the VIX has more accuracy than the consumer pessimism for both in-sample and out-of-sample forecasts. In the out-of-sample case, the forecasts are less accurate for both measures overall, but the discrepancy between consumer pessimism and VIX is smaller relative to the in-sample case. An important thesis of this paper is that the two forms of information dissemination proposed impact systemic risk in distinct ways and we find empirical evidence supporting this 
proposition. More importantly, while print-media consumer pessimism have been found to impact average returns, we do not find this to be the case for predicting tail risk, once we control for the VIX. Our suggestion is that the measure of consumer pessimism might in fact be dominated, in terms of predictive power for tail risk, by a relatively known forward looking measure of volatility, the VIX.

Whether or not this suggestion generalizes to other measures of consumer pessimism that are based on print-media and/or real-time is certainly a topic for future investigation. In addition, further research on other firms, sectors and industries may prove useful to better understand the information content and dissemination of state variables on systemic risk. 


\section{References}

Acemoglu, D., Ozdaglar, A., and Tahbaz-Salehi, A., 2013, "Systemic Risk and Stability in Financial Networks," Working Paper 18727, National Bureau of Economics Research, Cambridge, Massachusetts.

Adrian, T., and Brunnermeier, M. K., 2011, "CoVaR," Working Paper 17454, National Bureau of Economics Research, Cambridge, Massachusetts.

Aruoba, B.S., Diebold, F.X., and Scotti, C., 2009, "Real-Time Measurement of Business Conditions," Journal of Business and Economic Statistics, 27(4), 417-427.

Bisias, D. Flood, M., Lo, A. W., and Valavanis, S., 2012, "A survey of systemic risk analytics," Working Paper 0001, Office of Financial Research: US Department of Treasury.

Bloom, N., 2014, "Fluctuations in Uncertainty," Journal of Economic Perspectives, 28(2), 153-76.

Brunnermeier, M. K., 2009, “Deciphering the Liquidity and Credit Crunch 2007-2008," Journal of Economic Perspectives, 23(1), 77-100.

CBOE (2009) The CBOE volatility index-VIX. Chicago Board Options Exchange, Incorporated.

Chao, S., Hardle, W. K., and Wang, W., 2012, "Quantile Regression in Risk Calibration," SFB 649 Discussion Paper 2012-006, Humboldt University, Berlin, German.

Chen, H., De, P., Hu, Y., and Hwang, B-H., 2014, " Wisdom of Crowds: The Value of Stock

Opinions Transmitted Through Social Media," The review of financial studies, 27(5), 1367-1403.

Chernozhukov, V., and Umantsev, L., 2001, "Conditional value-at-risk: Aspects of modeling and estimation. " Empirical Economics, 26(1), 271-292

Cheung, Y-W., and Ng, L.K., 1996, "A Causality in Variance Test and its Application to Financial Market Prices," Journal of Econometrics, 72, 33-48.

Croushore, D., 2011, "Frontiers of Real-Time Data Analysis," Journal of Economic Literature, 49(1): $72-100$.

Da, Z., Engelberg, J., and Gao, P, 2011, "In Search of attention". Journal of Finance, 66(5), 1461-1499.

Dimpfl, T., and Jank, S., 2011," Can internet search queries help to predict stock market volatility?" Working Papers in Economics and Finance, No.18. University of Tübingen.

Engle, R., and Manganelli, S., 2004, "CAViaR: Conditional Autoregressive Value at Risk by Regression Quantiles," Journal of Business and Economic Statistics, 22(4), 367-381.

Garcia, D., 2013, "Sentiment during recessions," Journal of Finance, 2013, 68(3), 1267-1300.

Gertler, M., and Kiyotaki, N., 2010, Financial Intermediation and Credit Policy in Business Cycle Analysis. In Handbook of Monetary Economics, vol. 3 of Handbook of Monetary, Economics, edited by Benjamin M. F., and Michael W., chap. 11, 547-599. Elsevier.

Giannone, D., Reichlin,L., and David, S., 2008, "Nowcasting: The real-time informational content of macroeconomic data," Journal of Monetary Economics, 55(4), 665-676. 
Gray, D. F., and Jobst, A. J., 2011,"Modelling systemic financial sector and sovereign risk," Sveriges Riksbank Economic Review, 2:68 - 106.

Hansen, L. P., 2013, "Challenges in identifying and measuring systemic risk," Working Paper 18505 , National Bureau of Economics Research, Cambridge, Massachusetts.

Jegadeesh, N., and Wu, D., 2013 "Word Power: A New Approach for Content Analysis". Journal of Financial Economics, 110(1), 712-729.

Karabulut, Y., 2011 "Can Facebook Predict Stock Market Activity?" Available at SSRN: http://ssrn.com/abstract=1919008.

Kissan, J., Wintoki, M. B., and Zhang, Z., 2011,"Forecasting abnormal stock returns and trading volume using investor sentiment: Evidence from online search," International Journal of Forecasting, 27(4), 1116-1127.

Klubmann, A. G., and Hautsch, N., 2011," When machines read the news: Using automated text analytics to quantify high frequency news-implied market reactions," Journal of Empirical Finance, 18 (2011) 321-340.

Koenker, R. and Bassett, G., Jr., 1978, “Regression Quantiles,” Econometrica, 46(1), 33-50.

Kuan, CM., Yeh JH., and Hsu, YC., 2009, "Assessing value at risk with CARE, the conditional autoregressive expectile models," Journal of Econometrics, 150(2), 261-270.

Loughran, T., and B. McDonald, 2011, "When is a liability not a liability? Textual analysis, dictionaries, and 10-Ks," Journal of Finance, 66(1), 35-65.

Mao, H., Counts, S., and Bollen, J., 2011, " Predicting Financial Markets: Comparing Survey, News, Twitter and Search Engine Data," Quantitative Finance, arXiv:1112.1051

Merton, R. C., 1987, “A Simple Model of Capital Market Equilibrium with Incomplete Information,” The Journal of Finance, 42(3), 483-510.

Shiller, R. J., 2000, Irrational Exuberance. Princeton University Press, Princeton.

Tetlock, P. C., 2007, "Giving content to investor sentiment: the role of media in the stock market," Journal of Finance, 62(3), 1139-1168.

Uhl, M., 2012, " Reuters Sentiment and Stock Returns," Journal of Behavioral Finance, forthcoming.

Varian, Hal R. and Choi, Hyunyoung, Predicting the Present with Google Trends (April 2, 2009). SSRN: http://ssrn.com/abstract=1659302 or http://dx.doi.org/10.2139/ssrn.1659302 
Table 1: Summary of Data

\begin{tabular}{lcccccc}
\hline \hline Variable & Obs & Date Range & Mean & Std. Dev. & Min & Max \\
\hline Consumer pessimism (Pessi) & 3484 & $01 / 02 / 92 \sim 01 / 03 / 06$ & 0.0126331 & 0.0103836 & -0.019293 & 0.0664452 \\
VIX & 3483 & $01 / 02 / 92 \sim 01 / 03 / 06$ & 19.22203 & 6.523288 & 9.31 & 45.74 \\
S\&P500 index & 3487 & $01 / 02 / 92 \sim 01 / 03 / 06$ & 0.0001505 & 0.0044261 & -0.03089 & 0.0242043 \\
Change in the credit spread & 3485 & $01 / 02 / 92 \sim 01 / 03 / 06$ & -0.000284 & 0.028859 & -0.16 & 0.19 \\
Change in the slope of the yield curve & 3487 & $01 / 02 / 92 \sim 01 / 03 / 06$ & -0.001127 & 0.0614187 & -0.56 & 0.48 \\
Change in the three-month treasury bill rate & 3339 & $01 / 02 / 92 \sim 01 / 03 / 06$ & $-9.28 \mathrm{E}-05$ & 0.0400699 & -0.49 & 0.23 \\
Short term liquidity spread & 3487 & $01 / 02 / 92 \sim 01 / 03 / 06$ & 0.2220591 & 0.2012501 & -0.38 & 1.33 \\
Dow Jones US Real Estate index returns & 3487 & $01 / 02 / 92 \sim 01 / 03 / 06$ & 0.000101 & 0.003511 & -0.024803 & 0.0201852 \\
Citigroup (CITI) & 3487 & $01 / 02 / 92 \sim 01 / 03 / 06$ & 0.000417 & 0.0092968 & -0.074325 & 0.0731082 \\
American International Group Inc(AIG) & 3487 & $01 / 02 / 92 \sim 01 / 03 / 06$ & $-4.03 \mathrm{E}-05$ & 0.010185 & -0.183922 & 0.0454415 \\
Bank of America(BofA) & 3487 & $01 / 02 / 92 \sim 01 / 03 / 06$ & 0.0000337 & 0.0108156 & -0.309985 & 0.0366141 \\
Jefferies Group LLC(JEF) & 3486 & $01 / 02 / 92 \sim 01 / 03 / 06$ & 0.0002062 & 0.0161109 & -0.437613 & 0.1172139 \\
JPMorgan Chase \& Co(JP) & 3487 & $01 / 02 / 92 \sim 01 / 03 / 06$ & 0.0001058 & 0.0112469 & -0.308919 & 0.0645922 \\
Morgan Stanley(MS) & 3204 & $02 / 23 / 93 \sim 01 / 03 / 06$ & 0.00011 & 0.0133973 & -0.311986 & 0.0646178 \\
Goldman Sachs (GS) & 1652 & $05 / 05 / 99 \sim 01 / 03 / 06$ & 0.0003918 & 0.0241339 & -0.140604 & 0.1416211 \\
Raymond James Financial, Inc.(RJF) & 3481 & $01 / 02 / 92 \sim 01 / 03 / 06$ & 0.0000544 & 0.0116664 & -0.179172 & 0.0594062 \\
Stifel Financial Corporation(SF) & 3487 & $01 / 02 / 92 \sim 01 / 03 / 06$ & 0.0001984 & 0.009572 & -0.117551 & 0.1411361 \\
Wells Fargo(WF) & 3487 & $01 / 02 / 92 \sim 01 / 03 / 06$ & 0.0000746 & 0.0100464 & -0.298072 & 0.0529204 \\
Berkshire-Hathway(BRK) & 2398 & $05 / 10 / 96 \sim 01 / 03 / 06$ & 0.0001767 & 0.006481 & -0.03045 & 0.0482575 \\
Lehman Brother(LEH) & 2905 & $05 / 03 / 94 \sim 01 / 03 / 06$ & 0.0004583 & 0.0119122 & -0.089234 & 0.0765983 \\
Merrill Lynch(MLC) & 3484 & $01 / 02 / 92 \sim 01 / 03 / 06$ & 0.0003357 & 0.010394 & -0.053409 & 0.0610086 \\
Bear Stearns(BSC) & 3484 & $01 / 02 / 92 \sim 01 / 03 / 06$ & 0.0003479 & 0.0094788 & -0.046376 & 0.0699963 \\
\hline \hline
\end{tabular}


Table 2 CoVaR Estimations with External Effects of Pessi - CITI, AIG and BOA. This table reports the coefficients from regressions of the 5\% CoVaR on the daily returns of the alternative institutions where $\mathrm{j}=\mathrm{CITI}, \mathrm{AIG}$ and BOA respectively. We ran the VaR regression (3) and the table gives the coefficients of the quantile regression (5) $\mathrm{X}_{\mathrm{j}, \mathrm{t}}=\alpha_{\mathrm{j} \mid \mathrm{i}}+\pi_{1 \mathrm{j} \mid \mathrm{i}} \mathrm{I}_{\mathrm{t}, \mathrm{t}-1}+\pi_{2 \mathrm{j} \mid \mathrm{i}}\left(\mathrm{ID}_{\mathrm{t}, \mathrm{t}-1} \times \mathrm{X}_{\mathrm{i}, \mathrm{t}}\right)+\beta_{\mathrm{j} \mid \mathrm{i}} \mathrm{X}_{\mathrm{i}, \mathrm{t}}+\gamma_{\mathrm{j} \mid \mathrm{i}}^{\mathrm{T}} \mathrm{M}_{\mathrm{t}-1}+\varepsilon_{\mathrm{j}, \mathrm{t}}$ where $\mathrm{ID}_{\mathrm{t}, \mathrm{t}-1}$ is pessi. For example, in column (1), it shows the estimating results when $\mathrm{j}=\mathrm{CITI}$ and $\mathrm{i}=\mathrm{AIG}$, thus 0.4647 is the coefficient for AIG, -0.0156 is the coefficient of pessi while 11.2757 is the coefficient of the interaction between AIG and pessi.

\begin{tabular}{|c|c|c|c|c|c|c|c|c|c|c|c|c|c|}
\hline $\begin{array}{l}\mathbf{j}=\mathrm{CITI} \\
\mathrm{i}=\end{array}$ & $\begin{array}{l}\text { (1) } \\
\text { AIG }\end{array}$ & $\begin{array}{l}\text { (2) } \\
\text { BOA } \\
\end{array}$ & $\begin{array}{l}\text { (3) } \\
\text { JEF }\end{array}$ & $\begin{array}{l}\text { (4) } \\
\text { JP }\end{array}$ & $\begin{array}{l}\text { (5) } \\
\text { MS }\end{array}$ & $\begin{array}{l}\text { (6) } \\
\text { GS }\end{array}$ & $\begin{array}{l}\text { (7) } \\
\text { RJF }\end{array}$ & $\begin{array}{l}\text { (8) } \\
\text { SF }\end{array}$ & $\begin{array}{l}\text { (9) } \\
\text { WF }\end{array}$ & $\begin{array}{l}\text { (10) } \\
\text { BRK }\end{array}$ & $\begin{array}{l}\text { (11) } \\
\text { LEH }\end{array}$ & $\begin{array}{l}\text { (12) } \\
\text { MLC }\end{array}$ & $\begin{array}{l}\text { (13) } \\
\text { BSC }\end{array}$ \\
\hline institution & i $0.4647 * * *$ & $0.6390 * * *$ & $0.0975 * * *$ & $0.4923 * * *$ & $0.3984 * * *$ & 0.1379 & $0.1988 * *$ & 0.0378 & $0.4675^{* * *}$ & 0.2372 & $0.3037 * * *$ & $0.4117 * * *$ & $0.3675^{* * *}$ \\
\hline pessi & -0.0156 & 0.0025 & -0.0110 & 0.0321 & 0.0219 & 0.0074 & -0.0107 & -0.0806 & $-0.0768^{*}$ & $-0.1338 * *$ & 0.0087 & 0.0262 & 0.0345 \\
\hline pessi*i & $11.2757^{* * *}$ & * 3.4598 & $14.0259^{* * *}$ & $* 9.8797 * * *$ & $6.7619^{* *}$ & 5.2071 & $12.3409^{*}$ & 9.7170 & $13.8772 * * *$ & * 16.2498 & 7.2959 & 7.3527 & $9.5962 *$ \\
\hline$\overline{\mathbf{j}=\mathrm{AIG}}$ & (14) & (15) & (16) & (17) & (18) & (19) & (20) & (21) & (22) & (23) & (24) & (25) & (26) \\
\hline $\mathrm{i}=$ & CITI & BOA & JEF & JP & MS & GS & RJF & SF & WF & BRK & LEH & MLC & BSC \\
\hline institution & i $0.3239 * * *$ & $0.3728 * * *$ & 0.0329 & $0.2736^{* * *}$ & $0.2157 * * *$ & 0.0396 & $0.1728^{* *}$ & 0.0311 & $0.4484 * * *$ & 0.2958 & $0.1987 * * *$ & $0.2488^{* * *}$ & $0.2480^{* * *}$ \\
\hline pessi & $-0.0620 *$ & -0.0418 & $-0.0978^{* *}$ & -0.0280 & -0.0473 & -0.0729 & -0.0617 & $-0.1222 * *$ & $-0.0855^{*}$ & $-0.0906^{*}$ & $-0.0972 * *$ & -0.0653 & $-0.0892 * *$ \\
\hline pessi*i & 5.5764 & 5.1850 & $12.0507 * * *$ & * $6.2182 * * *$ & 3.7604* & $7.8066^{* *}$ & 7.3016* & 6.9624 & $5.2554 *$ & 6.6609 & $5.9344 *$ & 5.6274 & $7.4783^{* *}$ \\
\hline$\overline{\mathbf{j}=\mathrm{BOA}}$ & (27) & (28) & (29) & (30) & (31) & (32) & (33) & (34) & (35) & (36) & (37) & (38) & (39) \\
\hline $\mathbf{i}=$ & CITI & AIG & JEF & JP & MS & GS & RJF & SF & WF & BRK & LEH & MLC & BSC \\
\hline institution & i $0.4131^{* * *}$ & $0.3648 * * *$ & $0.0807^{* * *}$ & $0.4567 * * *$ & $0.3169 * * *$ & 0.0463 & $0.1736^{* * *}$ & 0.0129 & $0.5741^{* * *}$ & 0.1453 & $0.2399 * *$ & $0.3273^{* * *}$ & $0.2912^{* * *}$ \\
\hline pessi & -0.0522 & $-0.0584 *$ & $-0.1040^{* *}$ & -0.0233 & -0.0447 & -0.0389 & $-0.0793 *$ & $-0.1410^{* * *}$ & $-0.0776^{* *}$ & -0.0872 & -0.0356 & $-0.0709^{*}$ & -0.0515 \\
\hline pessi*i & 5.8662 & $11.1387^{* * *}$ & $7.9467 * * *$ & $3.2780 *$ & 3.0699 & 5.5748 & 5.8583 & 7.2012 & $6.3482 * *$ & 10.0362 & 6.9806 & 4.2604 & $7.5516^{*}$ \\
\hline
\end{tabular}

\footnotetext{
Notes: ${ }^{*} p<0.05,{ }^{* *} p<0.01,{ }^{* * *} p<0.001$
} 
Table 3 CoVaR Estimations with External Effects of VIX - CITI, AIG and BOA. This table reports the coefficients from regressions of the $5 \%$ CoVaR on the daily returns of the alternative institutions where $\mathrm{j}=\mathrm{CITI}$, AIG and BOA respectively. We ran the VaR regression (3) and the table gives the coefficients of the quantile regression (5) $\mathrm{X}_{\mathrm{j}, \mathrm{t}}=\alpha_{\mathrm{j} \mid \mathrm{i}}+\pi_{1 \mathrm{j} \mid \mathrm{i}} \mathrm{I}_{\mathrm{t}, \mathrm{t}-1}+\pi_{2 \mathrm{j} \mid \mathrm{i}}\left(\mathrm{ID}_{\mathrm{t}, \mathrm{t}-1} \times \mathrm{X}_{\mathrm{i}, \mathrm{t}}\right)+\beta_{\mathrm{j} \mid \mathrm{i}} \mathrm{X}_{\mathrm{i}, \mathrm{t}}+\gamma_{\mathrm{j} \mid \mathrm{i}}^{\mathrm{T}} \mathrm{M}_{\mathrm{t}-1}+\varepsilon_{\mathrm{j}, \mathrm{t}}$ where $\mathrm{ID}_{\mathrm{t}, \mathrm{t}-1}$ isVIX. For example, in column (1), it shows the estimating results when $\mathrm{j}=\mathrm{CITI}$ and $\mathrm{i}=\mathrm{AIG}$, thus -0.0096 is the coefficient for AIG, -0.0003 is the coefficient of VIX while 0.0292 is the coefficient of the interaction between AIG and VIX.

\begin{tabular}{|c|c|c|c|c|c|c|c|c|c|c|c|c|c|}
\hline $\mathbf{j}=\mathbf{C I T I}$ & (1) & (2) & (3) & (4) & (5) & (6) & (7) & (8) & (9) & (10) & (11) & (12) & (13) \\
\hline $\mathbf{i}=$ & AIG & BOA & JEF & JP & MS & GS & RJF & SF & WF & BRK & LEH & MLC & BSC \\
\hline institution $\mathrm{i}$ & -0.0096 & $0.3751 * * *$ & $-0.3580 * * *$ & $0.2409 *$ & 0.1556 & -0.1763 & -0.1311 & -0.1281 & -0.0654 & -0.0754 & 0.0611 & 0.2966 & 0.0547 \\
\hline vix & $-0.0003 * * *$ & $-0.0003 * * *$ & $-0.0003 * * *$ & $-0.0002 * *$ & $-0.0002 * * *$ & $-0.0005 * * *$ & $-0.0003 * * *$ & $-0.0005 * * *$ & $-0.0004 * * *$ & $-0.0008 * * *$ & $-0.0003 * * *$ & $-0.0002 * * *$ & $-0.0002 * * *$ \\
\hline vix*i & $0.0292 * * *$ & $0.0137 * *$ & $0.0296 * * *$ & $0.0141 * *$ & $0.0140 * *$ & $0.0163 * * *$ & $0.0214 * * *$ & 0.0115 & $0.0341 * * *$ & 0.0207 & 0.0136 & 0.0100 & $0.0192 *$ \\
\hline $\mathbf{j}=\mathbf{A I G}$ & (14) & (15) & (16) & (17) & (18) & (19) & (20) & (21) & (22) & (23) & (24) & (25) & (26) \\
\hline $\mathrm{i}=$ & CITI & BOA & JEF & JP & MS & GS & RJF & SF & WF & BRK & LEH & MLC & BSC \\
\hline institution $\mathrm{i}$ & 0.1539 & $0.2250 * *$ & $-0.2484 * * *$ & 0.1220 & 0.2028 & -0.0323 & -0.0993 & -0.1987 & 0.0085 & 0.2084 & 0.1819 & 0.2091 & 0.1219 \\
\hline vix & $-0.0003 * * *$ & $-0.0003 * * *$ & $-0.0004 * * *$ & $-0.0003 * * *$ & $-0.0003 * * *$ & $-0.0004 * * *$ & $-0.0004 * * *$ & $-0.0004 * * *$ & $-0.0004 * * *$ & $-0.0005 * * *$ & $-0.0003 * * *$ & $-0.0004 * * *$ & $-0.0004 * * *$ \\
\hline $\mathbf{v i x}^{*} \mathbf{i}$ & $0.0109 * *$ & $0.0079 *$ & $0.0198 * * *$ & $0.0105^{*}$ & 0.0031 & 0.0065 & $0.0158 * * *$ & $0.0136^{*}$ & $0.0212 * * *$ & 0.0045 & 0.0024 & 0.0035 & 0.0087 \\
\hline $\mathbf{j}=\mathbf{B O A}$ & (27) & (28) & (29) & (30) & (31) & (32) & (33) & (34) & (35) & (36) & (37) & (38) & (39) \\
\hline $\mathbf{i}=$ & CITI & AIG & JEF & JP & MS & GS & RJF & SF & WF & BRK & LEH & MLC & BSC \\
\hline institution $\mathrm{i}$ & 0.1033 & $0.2047 * *$ & $-0.1484 *$ & $0.5541 * * *$ & 0.0607 & 0.0835 & -0.0579 & -0.1425 & $0.2555 * * *$ & 0.3124 & 0.1740 & $0.2382 *$ & $0.2642 * *$ \\
\hline vix & $-0.0002 * * *$ & $-0.0003 * * *$ & $-0.0004 * * *$ & $-0.0003 * * *$ & $-0.0002 * * *$ & $-0.0004 * * *$ & $-0.0004 * * *$ & $-0.0004 * * *$ & $-0.0002 * * *$ & $-0.0006 * * *$ & $-0.0004 * * *$ & $-0.0003 * * *$ & $-0.0003 * * *$ \\
\hline $\mathbf{v i x} *_{i}$ & $0.0171 * *$ & $0.0133 * * *$ & $0.0174 * * *$ & -0.0016 & $0.0121 * *$ & 0.0021 & $0.0148 * * *$ & 0.0113 & $0.0174 * * *$ & -0.0009 & $0.0066 *$ & 0.0067 & 0.0043 \\
\hline
\end{tabular}

Notes: ${ }^{*} p<0.05, * * p<0.01, * * * p<0.001$ 
Table 4 CoVaR Estimations with External Effects of Pessi and VIX - CITI, AIG and BOA. This table reports the coefficients from regressions of the 5\% CoVaR on the daily returns of the alternative institutions where $\mathrm{j}=\mathrm{CITI}$. We ran the VaR regression (3) and the table gives the coefficients of the quantile regression (5)

$X_{j, t}=\alpha_{j \mid i}+\pi_{1 j \mid i} I D_{t, t-1}+\pi_{2 j \mid i}\left(I D_{t, t-1} \times X_{i, t}\right)+\beta_{j \mid i} X_{i, t}+\gamma_{j \mid i}^{T} M_{t-1}+\varepsilon_{j, t}$ where $I D_{t, t-1}$ is VIX and pessi. For example, in column (1), it shows the estimating results when $\mathrm{j}=\mathrm{CITI}$ and $\mathrm{i}=\mathrm{AIG}$, thus 0.0001 is the coefficient for AIG, 0.0694 is the coefficient of pessi while -0.0003 is the coefficient of VIX, 4.5566 is coefficient of the interaction between AIG and pessi, while 0.0254 is the coefficient of the interaction between AIG and VIX.

\begin{tabular}{|c|c|c|c|c|c|c|c|c|c|c|c|c|c|}
\hline $\begin{array}{l}\mathbf{j}=\mathrm{CITI} \\
\mathrm{i}=\end{array}$ & \begin{tabular}{|l}
$(1)$ \\
AIG
\end{tabular} & $\begin{array}{l}(2) \\
\text { BOA }\end{array}$ & $\begin{array}{l}\text { (3) } \\
\text { JEF }\end{array}$ & $\begin{array}{l}\text { (4) } \\
\text { JP }\end{array}$ & $\begin{array}{l}\text { (5) } \\
\text { MS }\end{array}$ & $\begin{array}{l}\text { (6) } \\
\text { GS }\end{array}$ & $\begin{array}{l}\text { (7) } \\
\text { RJF }\end{array}$ & $\begin{array}{l}\text { (8) } \\
\text { SF }\end{array}$ & $\begin{array}{l}\text { (9) } \\
\text { WF }\end{array}$ & $\begin{array}{l}(10) \\
\text { BRK }\end{array}$ & $\begin{array}{l}\text { (11) } \\
\text { LEH }\end{array}$ & $\begin{array}{l}\text { (12) } \\
\text { MLC }\end{array}$ & $\begin{array}{l}\text { (13) } \\
\text { BSC }\end{array}$ \\
\hline institution $\mathrm{i}$ & i 0.0001 & $0.3793 * * *$ & $-0.4414 * * *$ & $0.2768^{*}$ & 0.0634 & $-0.2242 *$ & -0.0769 & -0.1169 & -0.0947 & -0.1526 & 0.0066 & 0.2767 & 0.0380 \\
\hline pessi & $0.0694 *$ & 0.0498 & 0.0344 & 0.0404 & 0.0524 & 0.0172 & 0.0558 & 0.0070 & 0.0310 & 0.0116 & 0.0260 & $0.0710^{*}$ & $0.0693 *$ \\
\hline vix & $-0.0003 * * *$ & $-0.0003 * * *$ & $-0.0003 * * *$ & $-0.0002 * *$ & $-0.0002 * * *$ & $-0.0005 * * *$ & $-0.0003 * * *$ & $-0.0004 * * *$ & $-0.0004 * * *$ & $-0.0007 * * *$ & $-0.0002 * * *$ & $-0.0003 * * *$ & $-0.0002 * * *$ \\
\hline pessi*i & $4.5566^{* *}$ & 4.2869 & $11.9609 * * *$ & $2.9232 *$ & $6.0688^{*}$ & 4.4588 & 7.0220 & 4.6187 & $10.9267 * *$ & 14.3769 & 6.9744 & 5.8838 & $8.0289 *$ \\
\hline $\mathbf{v i x}^{*} \mathbf{i}$ & $0.0254 * * *$ & $0.0109 *$ & $0.0260 * * *$ & $0.0112 * *$ & $0.0137 * *$ & $0.0150 * *$ & $0.0151 * *$ & 0.0091 & $0.0258 * * *$ & 0.0142 & 0.0120 & 0.0064 & 0.0147 \\
\hline $\mathbf{j}=\mathbf{A I G}$ & (14) & (15) & (16) & (17) & (18) & (19) & (20) & (21) & (22) & (23) & (24) & (25) & (26) \\
\hline $\mathbf{i}=$ & CITI & BOA & JEF & JP & MS & GS & RJF & SF & WF & BRK & LEH & MLC & BSC \\
\hline institution i & 0.1068 & $0.2225^{* *}$ & $-0.3095 * * *$ & 0.1438 & 0.1527 & -0.1082 & $-0.2036^{*}$ & -0.2030 & 0.0255 & 0.3105 & 0.1233 & 0.1586 & 0.1133 \\
\hline pessi & -0.0134 & 0.0472 & 0.0022 & 0.0284 & 0.0092 & -0.0026 & -0.0040 & -0.0297 & -0.0031 & 0.0279 & -0.0010 & 0.0063 & -0.0293 \\
\hline vix & $-0.0003 * * *$ & $-0.0004 * * *$ & $-0.0004 * * *$ & $-0.0004 * * *$ & $-0.0004 * * *$ & $-0.0003 * * *$ & $-0.0004 * * *$ & $-0.0004 * * *$ & $-0.0004 * * *$ & $-0.0005^{* * *}$ & $-0.0004 * * *$ & $-0.0004 * * *$ & $-0.0004 * * *$ \\
\hline pessi*i & 3.5591 & 2.7841 & $7.1036^{* * *}$ & $5.2164 * * *$ & 2.2094 & $6.9167 * *$ & 5.8536 & 0.2204 & 0.8059 & 4.0268 & 3.6446 & 1.6774 & $6.6225^{*}$ \\
\hline vix*i & $0.0112 * *$ & 0.0065 & $0.0188 * * *$ & 0.0067 & 0.0038 & 0.0064 & $0.0165 * * *$ & $0.0132 *$ & $0.0200 * * *$ & 0.0001 & 0.0028 & 0.0048 & 0.0057 \\
\hline$\overline{\mathrm{j}}=\mathrm{BOA}$ & (27) & (28) & (29) & (30) & (31) & (32) & (33) & (34) & (35) & (36) & (37) & (38) & (39) \\
\hline $\mathrm{i}=$ & CITI & AIG & JEF & JP & MS & GS & RJF & SF & WF & BRK & LEH & MLC & BSC \\
\hline institution i & 0.0708 & 0.0210 & $-0.2205 * * *$ & $0.5132 * * *$ & 0.0529 & 0.0368 & -0.0625 & -0.0993 & $0.2319 * *$ & 0.2498 & 0.0742 & $0.2055^{*}$ & $0.2050 *$ \\
\hline pessi & -0.0140 & -0.0382 & -0.0273 & -0.0060 & -0.0169 & 0.0471 & -0.0299 & -0.0166 & -0.0481 & -0.0279 & 0.0241 & -0.0217 & -0.0290 \\
\hline vix & $-0.0002 * * *$ & $-0.0003 * * *$ & $-0.0003 * * *$ & $-0.0003 * * *$ & $-0.0002 * * *$ & $-0.0004 * * *$ & $-0.0003 * * *$ & $-0.0004 * * *$ & $-0.0003 * * *$ & $-0.0006 * * *$ & $-0.0004 * * *$ & $-0.0003 * * *$ & $-0.0003 * * *$ \\
\hline pessi*i $^{*}$ & 3.6068 & $8.7181 * * *$ & $6.0713 * * *$ & $3.0044 *$ & 0.6862 & 3.5676 & 3.8645 & 6.2972 & $4.9624 *$ & 7.8610 & 5.5414 & 2.6543 & $6.3824 * *$ \\
\hline vix*i & $0.0163 *$ & $0.0172 * * *$ & $0.0159 * * *$ & -0.0020 & $0.0122 *$ & 0.0016 & $0.0119 * *$ & 0.0051 & $0.0140 * *$ & -0.0033 & $0.0070 *$ & 0.0068 & 0.0035 \\
\hline
\end{tabular}

Notes: ${ }^{*} p<0.05, * * p<0.01,{ }^{* * *} p<0.001$ 
Table 5: Granger Causality Tests - Consumer pessimism (pessi) - VIX Asymptotic Chi-Square reported.

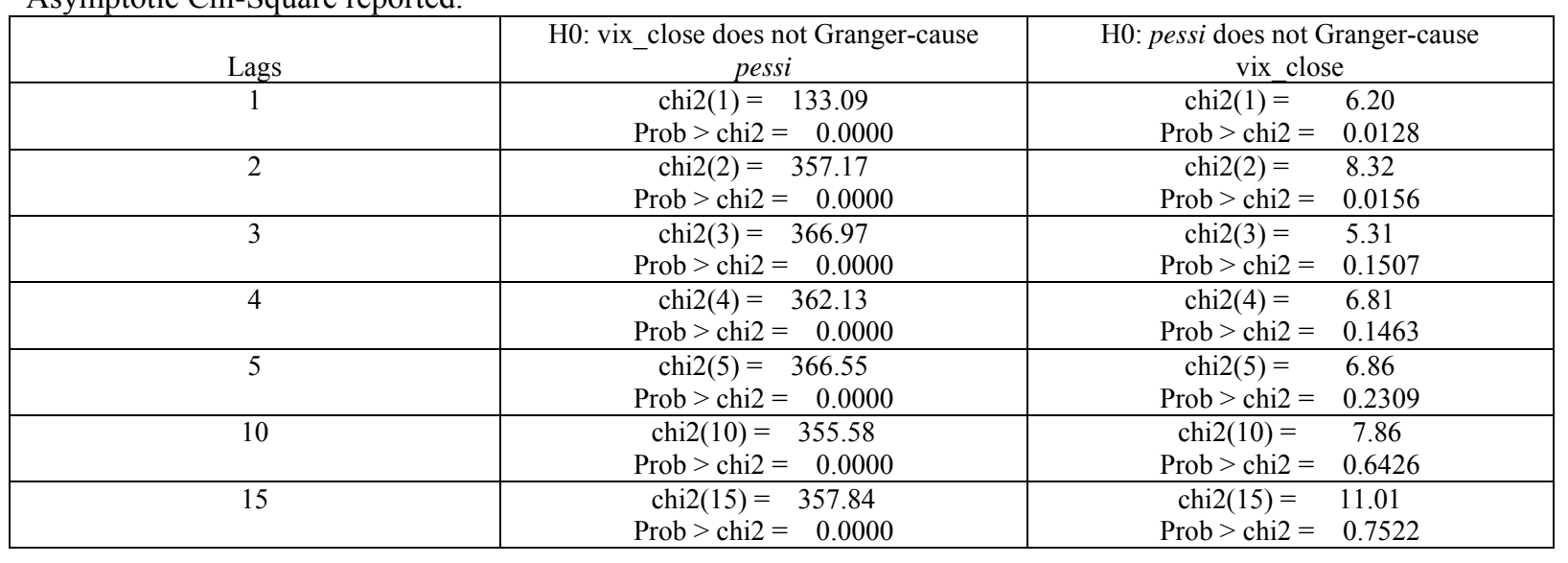

Table 6: Variance Causality Tests - Consumer pessimism (pessi) - VIX -

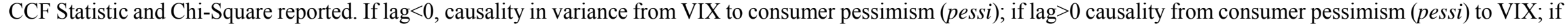
lag $=0$, feedback in variance in the same day.

\begin{tabular}{|c|c|c|c|}
\hline Lags & cross_corr_pessi_vix & CCF-Statistic & chi2_sample \\
\hline-13 & 0.06769 & 0.004582 & 15.8674 \\
\hline 0 & 0.04418 & 0.001953 & 6.7619 \\
\hline 6 & 0.03950 & 0.001561 & 5.4055 \\
\hline & & & $\chi_{1,0.05}^{2}=3.8414$ \\
\hline
\end{tabular}




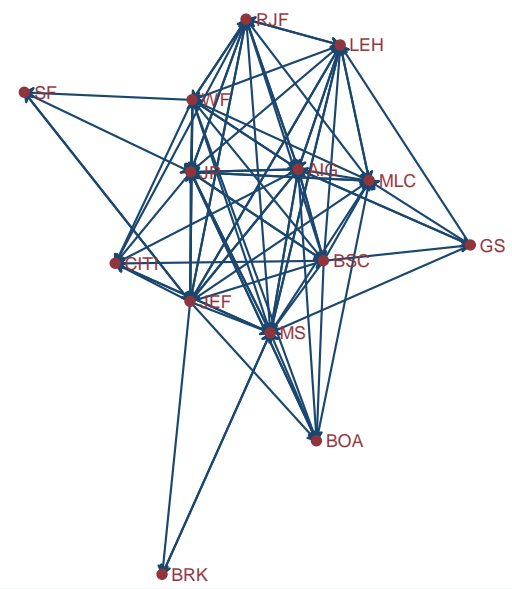

Figure 1.1 Stress of institution i through pessi on $\mathrm{j}$

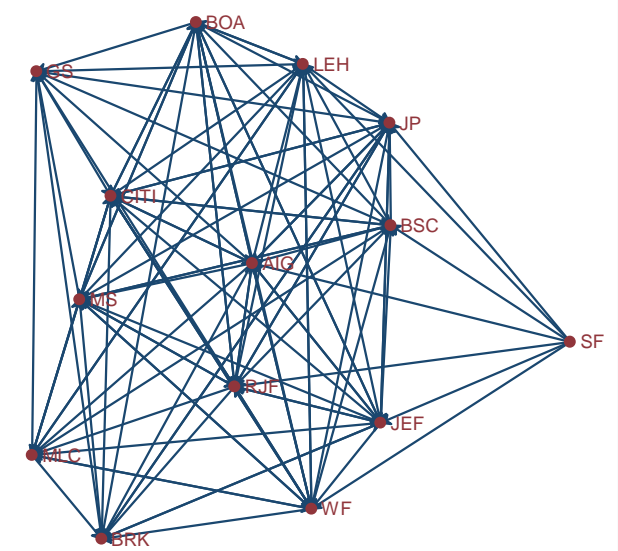

Figure 2.1 Stress of institution $\mathrm{i}$ through VIX on $\mathrm{j}$

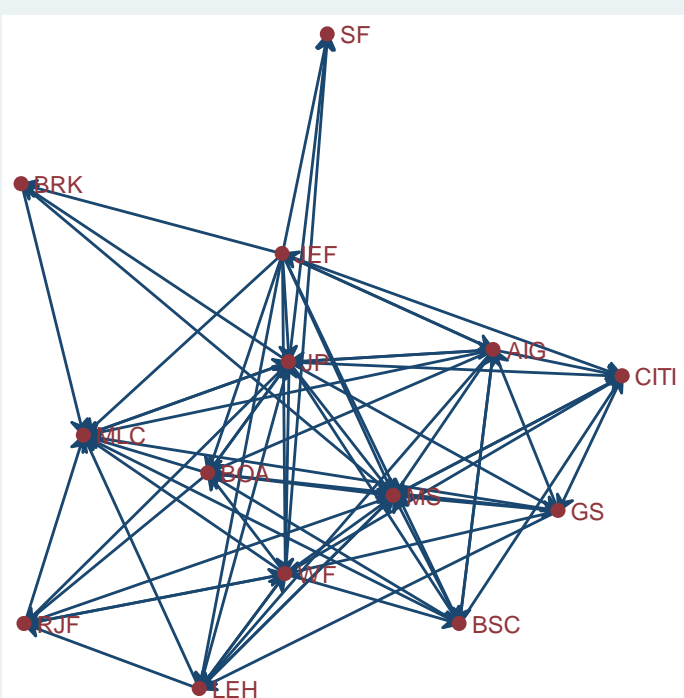

(a). Stress of institution i through pessi on j - VIX included

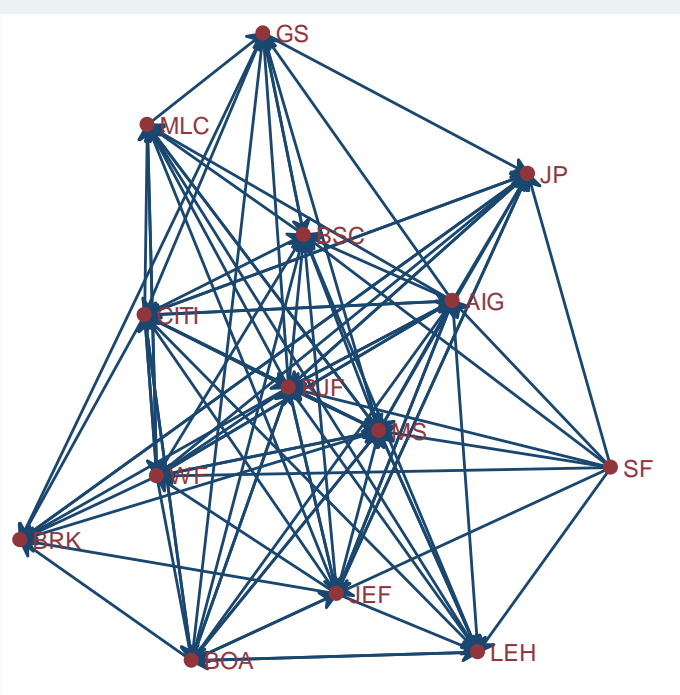

(b). Stress of institution i through VIX on $\mathrm{j}$ - pessi included Figure 3.1 Stress of institution $i$ through pessi and VIX on $j$

Note: Each arrow indicates the statistically significant effect of institution $i$ on institution $j$ via the interaction of institution i with pessi(Figure1.1)./VIX(Figure2.1)/pessi and VIX(Figure3.1). In these figures, the more arrows on one spot(institution $\mathrm{j}$ ), indicates that the more external stress from other institutions through information dissemination the spot(institution $\mathrm{j}$ ) has 

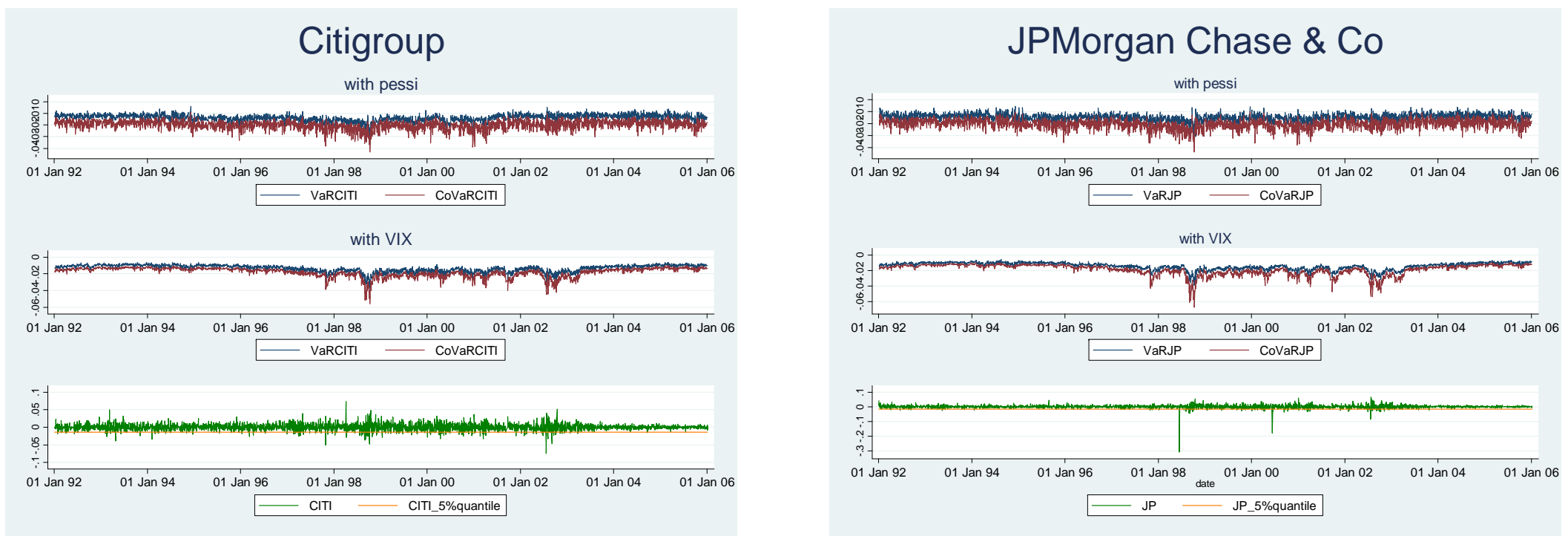

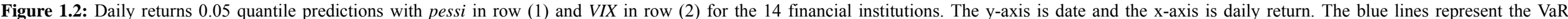

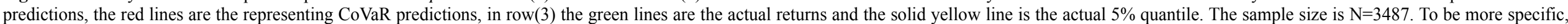

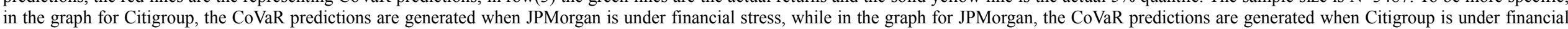

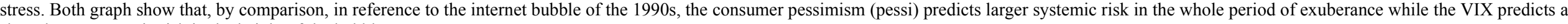
sharp larger systemic risk in the height of the bubble.
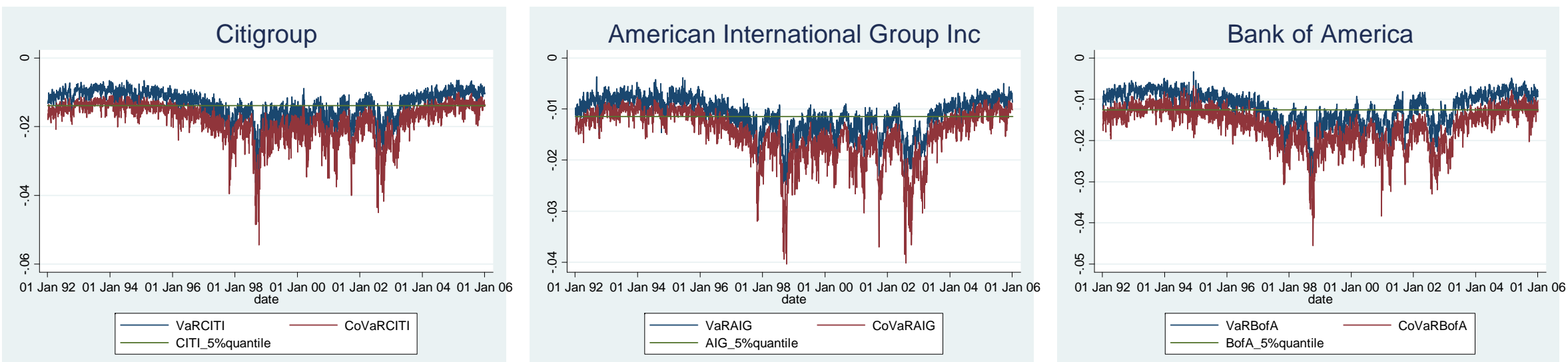

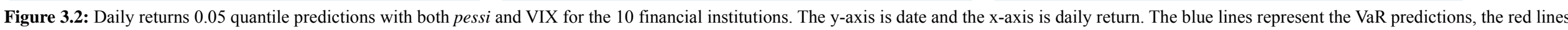
are the representing CoVaR predictions and the horizontal green lines are the actual $5 \%$ quantile. The sample size $\mathrm{N}=3487$. 

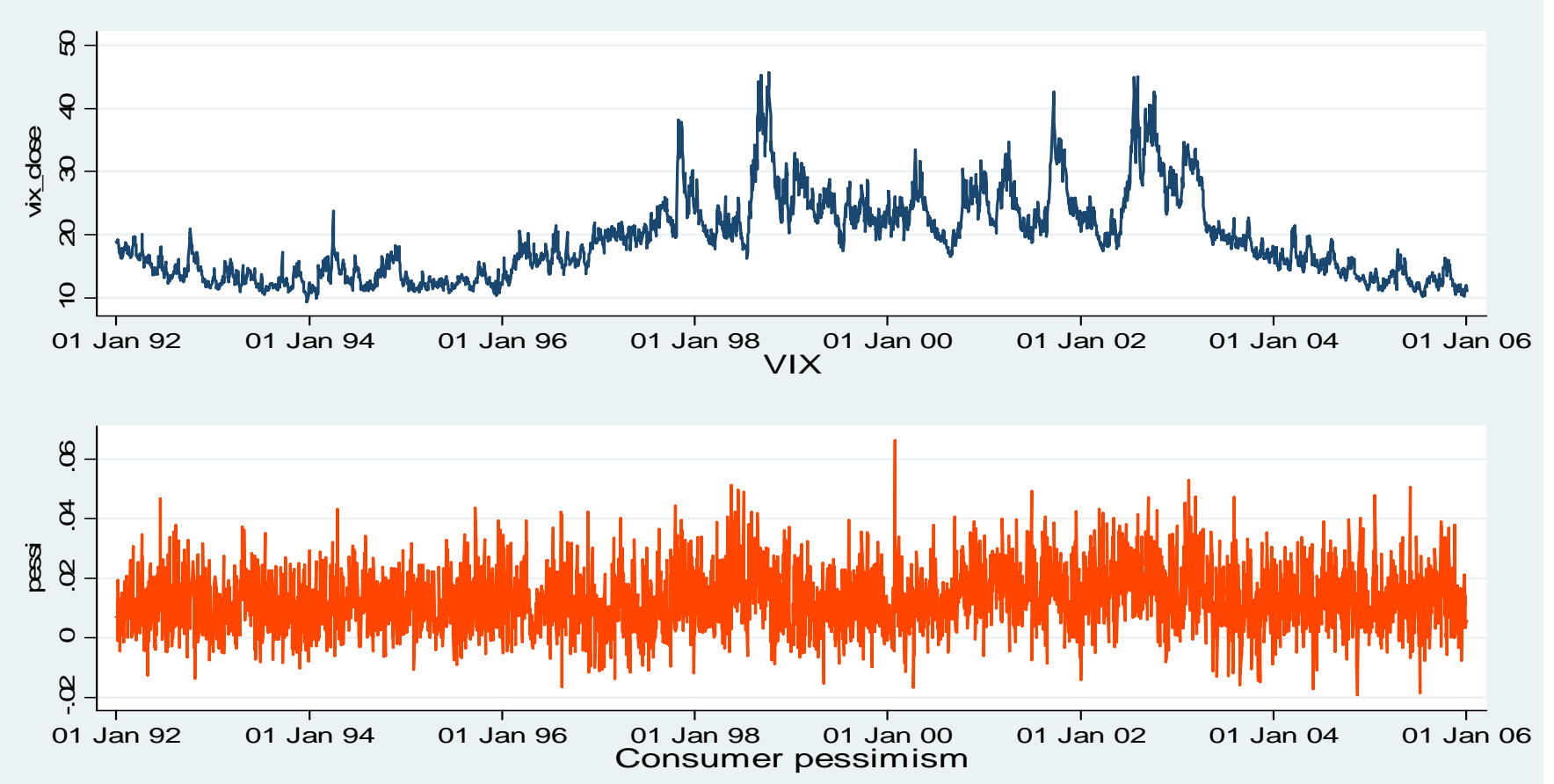

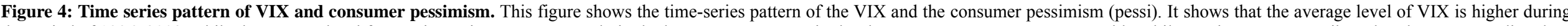

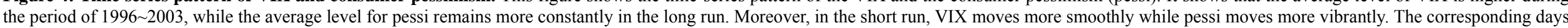

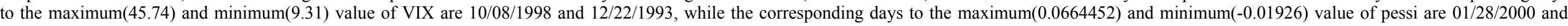
11/15/2004 
APPENDIX (NOT FOR PUBLICATION, TO BE AVAILABLE ONLINE TOGETHER WITH DATA)

Table A1 CoVaR Estimations with External Effects of Pessi - JEF, JP, MS and GS

\begin{tabular}{|c|c|c|c|c|c|c|c|c|c|c|c|c|c|}
\hline $\mathbf{J}=\mathbf{J E F}$ & $(40)$ & (41) & (42) & (43) & (44) & (45) & (46) & (47) & (48) & (49) & (50) & (51) & (52) \\
\hline $\mathbf{I}=$ & CITI & AIG & BOA & JP & MS & GS & RJF & SF & WF & BRK & LEH & MLC & BSC \\
\hline institution i & 0.1651 & 0.0455 & 0.1173 & $0.1923 *$ & $0.3289 * * *$ & $0.1479 * * *$ & $0.1664^{*}$ & -0.0427 & $0.0863 *$ & 0.0916 & $0.2433 * * *$ & $0.2149^{*}$ & 0.1381 \\
\hline pessi & -0.0394 & -0.0668 & $-0.1252 *$ & -0.0645 & -0.0976 & -0.0583 & -0.0619 & $-0.1095 *$ & -0.0841 & -0.1068 & -0.0553 & -0.0663 & -0.0858 \\
\hline pessi*i & 8.9302 & $14.9440 * * *$ & 9.1240 & 3.1808 & 0.4472 & 1.1980 & $10.8883^{*}$ & $11.6370^{*}$ & $15.8926 * * *$ & 3.5471 & $7.2349 *$ & 6.2260 & 9.7092 \\
\hline $\mathbf{J}=\mathbf{J P}$ & (53) & (54) & (55) & (56) & (57) & (58) & (59) & (60) & (61) & (62) & (63) & (64) & (65) \\
\hline$I=$ & CITI & AIG & BOA & JEF & MS & GS & RJF & SF & WF & BRK & LEH & MLC & BSC \\
\hline institution $\mathrm{i}$ & i $0.4869 * * *$ & $0.4347 * * *$ & $0.6515 * * *$ & 0.0249 & $0.4089 * * *$ & 0.1558 & $0.2140 * *$ & 0.0366 & $0.5129 * * *$ & 0.1312 & $0.3222 * * *$ & $0.3841 * * *$ & $0.3795 * * *$ \\
\hline pessi & $-0.0884 *$ & $-0.1074 * *$ & $-0.1031 * *$ & $-0.1286 * *$ & $-0.1003 *$ & -0.1007 & $-0.1340 * * *$ & $-0.1518 * *$ & $-0.1532 * * *$ & $-0.2599 * * *$ & $-0.1050 *$ & $-0.0870 *$ & $-0.0770 *$ \\
\hline pessi*i & 9.0484 & $16.3055^{* * *} *$ & $8.5347^{*}$ & $14.7725 * * *$ & $7.4075^{* *}$ & 5.9684 & $15.3954 * *$ & $9.3039 *$ & $16.5437 * * *$ & 13.7864 & 5.2933 & $9.7224 *$ & $11.4510 * *$ \\
\hline $\mathbf{J}=\mathbf{M S}$ & (66) & (67) & (68) & (69) & (70) & (71) & (72) & (73) & (74) & (75) & (76) & (77) & (78) \\
\hline $\mathbf{I}=$ & CITI & AIG & BOA & JEF & JP & GS & RJF & SF & WF & BRK & LEH & MLC & BSC \\
\hline institution $\mathrm{i}$ & i $0.5333 * * *$ & $0.4371 * * *$ & $0.5471 * * *$ & $0.1905^{* * *}$ & $0.4793 * * *$ & $0.3219 * * *$ & $0.2893 * * *$ & 0.0808 & $0.3828 * * *$ & 0.0893 & $0.5212 * * *$ & $0.6597 * * *$ & $0.4996 * * *$ \\
\hline pessi & -0.0385 & -0.0790 & $-0.1169 *$ & $-0.1612 * * *$ & -0.0572 & -0.0385 & $-0.0986^{*}$ & $-0.2355 * * *$ & $-0.1534 * *$ & $-0.2464 * * *$ & $-0.0879 * *$ & $-0.0700 *$ & -0.0370 \\
\hline pessi*i & $14.0497 * *$ & $19.4206^{* * *}$ & 13.3926* & $14.6807 * * *$ & $12.5152 * * *$ & $4.9937 *$ & $20.1805 * * *$ & 13.4838 & $24.5583 * * *$ & $21.4424 *$ & $9.7090 * *$ & 5.0850 & $16.9070 * * *$ \\
\hline $\mathbf{J}=\mathbf{G S}$ & (79) & (80) & (81) & (82) & (83) & (84) & (85) & (86) & (87) & (88) & (89) & (90) & (91) \\
\hline $\mathbf{I}=$ & CITI & AIG & BOA & JEF & JP & MS & RJF & SF & WF & BRK & LEH & MLC & BSC \\
\hline institution $\mathrm{i}$ & i $1.5007 * * *$ & $0.5826^{*}$ & $0.8658 * * *$ & $0.6243 * * *$ & $0.8058 * *$ & $1.5322 * * *$ & $1.1146^{* * *}$ & 0.2740 & 0.8096 & 0.1072 & $1.0728 * * *$ & $1.5405 * * *$ & $1.1153 * * *$ \\
\hline pessi & 0.0044 & -0.1256 & -0.1878 & -0.2128 & -0.0590 & -0.1094 & -0.2028 & $-0.3847^{*}$ & -0.2177 & $-0.3630 * *$ & -0.1302 & -0.1430 & -0.1659 \\
\hline pessi*i & 1.2820 & $34.1709 * *$ & 29.4815 & 9.9650 & 18.6623 & 4.7838 & 12.5465 & 6.8385 & 22.5673 & 32.1638 & 17.1639 & 7.6982 & $26.5583^{*}$ \\
\hline
\end{tabular}


Table A1. Cont. CoVaR Estimations with External Effects of Pessi - RJF, SF, WF and BRK

\begin{tabular}{|c|c|c|c|c|c|c|c|c|c|c|c|c|c|}
\hline $\mathbf{J}=\mathbf{R J F}$ & (92) & (93) & (94) & (95) & (96) & (97) & (98) & (99) & (100) & (101) & (102) & (103) & (104) \\
\hline$I=$ & CITI & AIG & BOA & JEF & $\mathbf{J P}$ & MS & GS & SF & WF & BRK & LEH & MLC & BSC \\
\hline institution $\mathrm{i}$ & i $0.3786 * * *$ & $0.3020 * * *$ & $0.3292 * * *$ & $0.1779 * * *$ & $0.3152 * * *$ & $0.4429 * * *$ & $0.1957 * * *$ & 0.0755 & $0.2844 * * *$ & 0.2224 & $0.3031 * * *$ & $0.5168 * * *$ & $0.5102 * * *$ \\
\hline pessi & 0.0287 & 0.0020 & -0.0220 & -0.0438 & 0.0272 & 0.0237 & -0.0237 & -0.0536 & -0.0083 & -0.0697 & 0.0044 & 0.0197 & -0.0214 \\
\hline pessi*i & 6.4815 & $11.6264 * * *$ & 10.1209 & $5.9006^{* *}$ & $7.7911 * * *$ & -0.0557 & 0.8943 & 8.2837 & $11.0216^{* *}$ & 4.2378 & $7.5636^{*}$ & -2.0329 & 1.8127 \\
\hline $\mathbf{J}=\mathbf{S F}$ & (105) & (106) & (107) & (108) & (109) & (110) & (111) & (112) & (113) & (114) & (115) & (116) & (117) \\
\hline $\mathbf{I}=$ & CITI & AIG & BOA & JEF & $\mathbf{J P}$ & MS & GS & RJF & WF & BRK & LEH & MLC & BSC \\
\hline institution $\mathrm{i}$ & $0.2136^{*}$ & 0.0794 & 0.0231 & -0.0277 & $0.1476^{*}$ & $0.1188 * * *$ & $0.1018^{* *}$ & $0.1474 *$ & $0.1273 * * *$ & 0.1484 & 0.1399 & $0.2474 * *$ & 0.0911 \\
\hline pessi & 0.0233 & 0.0418 & 0.0136 & 0.0182 & 0.0595 & -0.0014 & $0.1068 *$ & 0.0415 & 0.0557 & -0.0172 & 0.0001 & 0.0424 & 0.0043 \\
\hline pessi*i & 2.8137 & 4.9792 & 13.3315 & $10.7482 * * *$ & 3.3492 & 3.5191 & -2.1676 & 6.1289 & $9.6151 *$ & 6.0788 & 2.6570 & -0.2083 & 10.2269 \\
\hline $\mathbf{J}=\mathbf{W F}$ & (118) & (119) & (120) & (121) & (122) & (123) & (124) & (125) & (126) & (127) & (128) & (129) & (130) \\
\hline $\mathbf{I}=$ & CITI & AIG & BOA & JEF & JP & MS & GS & RJF & SF & BRK & LEH & MLC & BSC \\
\hline institution $\mathrm{i}$ & i $0.3071 * * *$ & $0.3482 * * *$ & $0.5109 * * *$ & 0.0061 & $0.3953 * * *$ & $0.2359 * * *$ & 0.0444 & $0.0978 *$ & 0.0365 & 0.1841 & $0.1495 * *$ & $0.1908 * *$ & $0.1867 * *$ \\
\hline pessi & 0.0165 & 0.0078 & 0.0526 & 0.0178 & 0.0203 & 0.0426 & -0.0495 & -0.0043 & -0.0012 & -0.0178 & 0.0124 & 0.0065 & 0.0063 \\
\hline pessi*i & 3.1277 & $2.9662 *$ & 0.5446 & $8.5767 * * *$ & 0.7761 & 2.0214 & 3.9789 & $7.7450 * *$ & 4.7635 & 1.2882 & $5.7975^{*}$ & 4.0691 & 6.4254 \\
\hline $\mathbf{J}=\mathbf{B R K}$ & (131) & (132) & (133) & (134) & (135) & (136) & (137) & (138) & (139) & (140) & (141) & (142) & (143) \\
\hline $\mathbf{I}=$ & CITI & AIG & BOA & JEF & $\mathbf{J P}$ & MS & GS & RJF & SF & WF & LEH & MLC & BSC \\
\hline institution i & 0.1106 & 0.0732 & 0.0383 & -0.0030 & 0.0270 & 0.0277 & 0.0058 & 0.0710 & 0.0444 & 0.1868 & 0.0871 & 0.0491 & 0.0751 \\
\hline pessi & -0.0336 & -0.0180 & -0.0086 & -0.0193 & -0.0092 & -0.0080 & -0.0341 & 0.0054 & -0.0129 & -0.0279 & -0.0021 & -0.0137 & -0.0020 \\
\hline pessi*i & 3.9488 & 2.1994 & 5.3061 & $5.4407 * *$ & 3.3064 & $4.6287 * *$ & 2.4199 & 4.2417 & 1.1101 & -2.2825 & 2.0325 & 2.8142 & 2.9091 \\
\hline
\end{tabular}


Table A1. Cont. CoVaR Estimations with External Effects of Pessi - LEH, MLC and BSC

\begin{tabular}{|c|c|c|c|c|c|c|c|c|c|c|c|c|c|}
\hline $\mathbf{J}=\mathbf{L E H}$ & (144) & (145) & (146) & (147) & (148) & (149) & (150) & (151) & (152) & (153) & (154) & (155) & (156) \\
\hline $\mathbf{I}=$ & CITI & AIG & BOA & JEF & JP & MS & GS & RJF & SF & WF & BRK & MLC & BSC \\
\hline institution & i $0.5500 * * *$ & $0.3630 * * *$ & $0.5977 * * *$ & $0.2098 * * *$ & $0.4458 * * *$ & $0.6012 * * *$ & $0.2898 * * *$ & $0.4424 * * *$ & 0.1834 & $0.4757 * * *$ & 0.1394 & $0.6184 * * *$ & $0.6378 * * *$ \\
\hline pessi & -0.0372 & -0.0624 & -0.0262 & $-0.1022 *$ & -0.0235 & 0.0196 & 0.0027 & $-0.0973 *$ & $-0.1553 * *$ & -0.1004 & $-0.1559 *$ & 0.0039 & 0.0114 \\
\hline pessi*i & 10.9966 & $19.6516^{* * *}$ & 10.2785 & $10.6209 * * *$ & $10.5471 * * *$ & $7.7803 * * *$ & $4.2129^{*}$ & $13.1235^{* *}$ & 8.4186 & 12.3588 & 15.3438 & $9.7732 *$ & $11.2040^{* *}$ \\
\hline $\mathbf{J}=\mathbf{M L C}$ & (157) & (158) & (159) & (160) & (161) & (162) & (163) & (164) & (165) & (166) & (167) & (168) & (169) \\
\hline $\mathbf{I}=$ & CITI & AIG & BOA & JEF & $\mathbf{J P}$ & MS & GS & RJF & SF & WF & BRK & LEH & BSC \\
\hline institution & i $0.5784 * * *$ & $0.3346^{* * *}$ & $0.4567 * * *$ & 0.0146 & $0.4653 * * *$ & $0.5342 * * *$ & $0.2271 * * *$ & $0.3060 * * *$ & 0.0569 & $0.4094 * * *$ & 0.0045 & $0.4661 * * *$ & $0.5477 * * *$ \\
\hline pessi & -0.0220 & -0.0615 & -0.0163 & -0.0677 & -0.0179 & 0.0024 & -0.0413 & -0.0741 & $-0.1661 * * *$ & $-0.0894 *$ & $-0.2007 * * *$ & 0.0194 & -0.0404 \\
\hline pessi*i & 6.0565 & $18.3854 * * *$ & $13.1616^{* * *}$ & $17.4062 * * *$ & $8.0510 * * *$ & $5.3257 * *$ & $5.2947^{*}$ & $10.5807^{*}$ & 12.4956 & $14.0112 * * *$ & 18.2187 & $7.8574 *$ & $10.6720 * *$ \\
\hline $\mathbf{J}=\mathbf{B S C}$ & (170) & (171) & (172) & (173) & (174) & (175) & (176) & (177) & (178) & (179) & (180) & (181) & (182) \\
\hline $\mathbf{I}=$ & CITI & AIG & BOA & JEF & JP & MS & GS & RJF & SF & WF & BRK & LEH & MLC \\
\hline institution & i $0.4662 * * *$ & $0.2775 * * *$ & $0.4891 * * *$ & $0.0907 * *$ & $0.3848 * * *$ & $0.4913 * * *$ & $0.2096 * * *$ & $0.3805 * * *$ & 0.0906 & $0.4081 * * *$ & 0.1316 & $0.4899 * * *$ & $0.5819 * * *$ \\
\hline pessi & -0.0266 & -0.0321 & -0.0173 & -0.0480 & 0.0074 & 0.0062 & -0.0188 & 0.0037 & $-0.0808 *$ & -0.0074 & -0.0773 & -0.0067 & 0.0005 \\
\hline pessi*i & 5.8437 & $18.6138 * * *$ & 6.9421 & $10.3744 * * *$ & $6.5815 * * *$ & 3.1908 & 3.5029 & $8.0388^{*}$ & 8.2421 & $9.9827 * * *$ & 13.5034 & 2.7078 & 3.1550 \\
\hline
\end{tabular}


Table A2 CoVaR Estimations with External Effects of VIX - JEF, JP, MS and GS

\begin{tabular}{|c|c|c|c|c|c|c|c|c|c|c|c|c|c|}
\hline $\mathbf{J}=\mathbf{J E F}$ & (40) & (41) & (42) & (43) & (44) & (45) & (46) & (47) & (48) & (49) & (50) & (51) & (52) \\
\hline$I=$ & CITI & AIG & BOA & JP & MS & GS & RJF & SF & WF & BRK & LEH & MLC & BSC \\
\hline institution i & -0.0627 & -0.1875 & $-0.4687^{*}$ & -0.1717 & 0.0564 & 0.1867 & -0.1325 & $-0.5783 * *$ & -0.1050 & -0.4395 & 0.1875 & -0.1189 & -0.1829 \\
\hline vix & -0.0000 & -0.0000 & 0.0000 & 0.0001 & -0.0001 & $-0.0004 * * *$ & 0.0001 & -0.0001 & -0.0001 & $-0.0004 * * *$ & $-0.0002^{*}$ & 0.0001 & -0.0001 \\
\hline vix*i & 0.0177 & $0.0200 * *$ & $0.0324 * * *$ & $0.0188^{*}$ & 0.0111 & -0.0009 & $0.0183 * *$ & $0.0322 * *$ & 0.0151 & $0.0267 *$ & 0.0063 & 0.0184 & 0.0214 \\
\hline $\mathbf{J}=\mathbf{J P}$ & (53) & (54) & (55) & (56) & (57) & (58) & (59) & (60) & (61) & (62) & (63) & (64) & (65) \\
\hline $\mathbf{I}=$ & CITI & AIG & BOA & JEF & MS & GS & RJF & SF & WF & BRK & LEH & MLC & BSC \\
\hline institution $\mathrm{i}$ & 0.0184 & -0.1772 & $0.5146 * * *$ & $-0.3693 * * *$ & 0.0999 & -0.0439 & -0.0908 & -0.2401 & $0.1895^{* *}$ & $-0.6859 * *$ & 0.1541 & 0.2647 & 0.0818 \\
\hline vix & $-0.0003 * * *$ & $-0.0005 * * *$ & $-0.0004 * * *$ & $-0.0005 * * *$ & $-0.0004 * * *$ & $-0.0007 * * *$ & $-0.0005 * * *$ & $-0.0006^{* * *}$ & $-0.0005 * * *$ & $-0.0009 * * *$ & $-0.0006 * * *$ & $-0.0004 * * *$ & $-0.0004 * * *$ \\
\hline vix*i & $0.0250 * * *$ & $0.0367 * * *$ & $0.0093 *$ & $0.0307 * * *$ & $0.0160 * * *$ & $0.0119 * * *$ & $0.0205 * * *$ & $0.0178^{*}$ & $0.0213 * * *$ & $0.0472 * * *$ & $0.0110^{*}$ & 0.0099 & $0.0183^{*}$ \\
\hline $\mathbf{J}=\mathbf{M S}$ & (66) & (67) & (68) & (69) & (70) & (71) & (72) & (73) & (74) & (75) & (76) & (77) & (78) \\
\hline $\mathbf{I}=$ & CITI & AIG & BOA & JEF & JP & GS & RJF & SF & WF & BRK & LEH & MLC & BSC \\
\hline institution $\mathrm{i}$ & 0.2241 & 0.1173 & 0.1071 & -0.1197 & 0.4145 & $0.3284 * * *$ & -0.1393 & -0.1196 & -0.0670 & -0.3238 & $0.3807^{*}$ & $0.2610^{*}$ & -0.0189 \\
\hline vix & $-0.0004 * * *$ & $-0.0005 * * *$ & $-0.0005 * * *$ & $-0.0006 * * *$ & $-0.0005 * * *$ & $-0.0004 * * *$ & $-0.0004 * * *$ & $-0.0007 * * *$ & $-0.0006 * * *$ & $-0.0009 * * *$ & $-0.0003 * * *$ & $-0.0003 * * *$ & $-0.0003 * * *$ \\
\hline vix*i & $0.0215^{* * *}$ & $0.0237 * * *$ & $0.0258 * * *$ & $0.0188 * *$ & 0.0105 & 0.0036 & $0.0317 * * *$ & 0.0157 & $0.0363 * * *$ & 0.0242 & 0.0110 & $0.0203 * * *$ & $0.0326 * * *$ \\
\hline$\overline{\mathbf{J}=\mathbf{G S}}$ & (79) & (80) & (81) & (82) & (83) & (84) & (85) & (86) & (87) & (88) & (89) & (90) & (91) \\
\hline$I=$ & CITI & AIG & BOA & JEF & JP & MS & RJF & SF & WF & BRK & LEH & MLC & BSC \\
\hline institution i & $1.3555^{* *}$ & -0.2810 & 0.3253 & $0.6886^{*}$ & $1.0321 * * *$ & $0.5698^{*}$ & 0.5143 & 0.0164 & 0.8079 & -0.5969 & $1.1890 * * *$ & $1.1064 * * *$ & -0.0180 \\
\hline vix & $-0.0011 * * *$ & $-0.0012 * * *$ & $-0.0013 * * *$ & $-0.0014 * * *$ & $-0.0013 * * *$ & $-0.0007 * * *$ & $-0.0010 * * *$ & $-0.0016 * * *$ & $-0.0014 * * *$ & $-0.0014 * * *$ & $-0.0009 * * *$ & $-0.0008 * * *$ & $-0.0010 * * *$ \\
\hline vix*i & 0.0103 & $0.0613 * * *$ & $0.0494 * * *$ & -0.0015 & 0.0111 & $0.0446^{* * *}$ & $0.0305^{*}$ & 0.0227 & 0.0188 & 0.0496 & 0.0032 & $0.0252 * *$ & $0.0632 * * *$ \\
\hline
\end{tabular}


Table A2 Cont. CoVaR Estimations with External Effects of VIX - RJF, SF, WF and BRK

\begin{tabular}{|c|c|c|c|c|c|c|c|c|c|c|c|c|c|}
\hline $\mathbf{J}=\mathbf{R J F}$ & (92) & (93) & (94) & (95) & (96) & (97) & (98) & (99) & (100) & (101) & (102) & (103) & (104) \\
\hline $\mathbf{I}=$ & CITI & AIG & BOA & JEF & JP & MS & GS & SF & WF & BRK & LEH & MLC & BSC \\
\hline institution $\mathrm{i}$ & $\mathrm{i}-0.0006$ & -0.0475 & -0.0235 & $-0.3064 * * *$ & 0.0348 & 0.1439 & 0.0941 & $-0.4828 * * *$ & 0.0329 & -0.1420 & $0.3004 *$ & 0.2317 & 0.2225 \\
\hline vix & $-0.0002 * * *$ & $-0.0003 * * *$ & $-0.0004 * * *$ & $-0.0003 * * *$ & $-0.0003 * * *$ & $-0.0002 * * *$ & $-0.0004 * * *$ & $-0.0005 * * *$ & $-0.0004 * * *$ & $-0.0006^{* * *}$ & $-0.0003 * * *$ & $-0.0002 * * *$ & $-0.0003 * * *$ \\
\hline $\mathbf{v i x}^{*} \mathbf{i}$ & $0.0212 * * *$ & $0.0207 * * *$ & $0.0204 * * *$ & $0.0251 * * *$ & $0.0157 * * *$ & $0.0112 *$ & 0.0039 & $0.0311 * * *$ & $0.0142 * *$ & 0.0171 & 0.0046 & 0.0088 & 0.0125 \\
\hline $\mathbf{J}=\mathbf{S F}$ & (105) & (106) & (107) & (108) & (109) & (110) & (111) & (112) & (113) & (114) & (115) & (116) & (117) \\
\hline $\mathbf{I}=$ & CITI & AIG & BOA & JEF & $\mathbf{J P}$ & MS & GS & RJF & WF & BRK & LEH & MLC & BSC \\
\hline institution $\mathrm{i}$ & 0.2624 & 0.1501 & 0.2206 & 0.0669 & $0.3061^{*}$ & 0.1062 & 0.1690 & 0.0232 & $0.2917 * * *$ & 0.0205 & 0.3077 & 0.3441 & 0.2905 \\
\hline vix & 0.0000 & 0.0001 & 0.0001 & $0.0002 *$ & $0.0001 *$ & 0.0000 & $0.0003 * *$ & 0.0000 & $0.0002 *$ & 0.0001 & 0.0001 & 0.0001 & 0.0001 \\
\hline vix*i & 0.0001 & 0.0007 & 0.0008 & 0.0011 & -0.0041 & 0.0035 & -0.0044 & 0.0087 & 0.0004 & 0.0061 & -0.0056 & -0.0045 & -0.0018 \\
\hline $\mathbf{J}=\mathbf{W F}$ & (118) & (119) & (120) & (121) & (122) & (123) & (124) & (125) & (126) & (127) & (128) & (129) & (130) \\
\hline $\mathbf{I}=$ & CITI & AIG & BOA & JEF & JP & MS & GS & RJF & SF & BRK & LEH & MLC & BSC \\
\hline institution $\mathrm{i}$ & $\mathrm{i} 0.1471$ & $0.1556^{*}$ & $0.4230 * * *$ & -0.1345 & $0.4188 * * *$ & 0.0482 & 0.0285 & -0.0164 & $-0.2912 * * *$ & 0.2910 & 0.1277 & 0.1074 & 0.1340 \\
\hline vix & $-0.0001 *$ & $-0.0001 * *$ & $-0.0001 *$ & $-0.0001 * *$ & $-0.0001 * *$ & $-0.0001 *$ & $-0.0004 * * *$ & $-0.0001 * * *$ & $-0.0002 * * *$ & $-0.0004 * * *$ & $-0.0003 * * *$ & $-0.0001 *$ & $-0.0002 * *$ \\
\hline vix*i & $0.0085 * *$ & $0.0113 * * *$ & 0.0038 & $0.0131 * * *$ & -0.0008 & $0.0096 * *$ & 0.0024 & $0.0102 * * *$ & $0.0180 * * *$ & -0.0051 & $0.0051 *$ & $0.0068^{*}$ & 0.0047 \\
\hline $\mathbf{J}=\mathbf{B R K}$ & (131) & (132) & (133) & (134) & (135) & (136) & (137) & (138) & (139) & (140) & (141) & (142) & (143) \\
\hline $\mathbf{I}=$ & CITI & AIG & BOA & JEF & $\mathbf{J P}$ & MS & GS & RJF & SF & WF & LEH & MLC & BSC \\
\hline institution i & $\mathrm{i}-0.1734$ & -0.1562 & $-0.2374 * * *$ & -0.1028 & $-0.3002 * * *$ & $-0.2454 * *$ & $-0.1958 * *$ & $-0.2946^{* *}$ & -0.1422 & -0.1371 & -0.0441 & -0.1420 & -0.0436 \\
\hline vix & $-0.0003 * * *$ & $-0.0003 * * *$ & $-0.0003 * * *$ & $-0.0002 * * *$ & $-0.0003 * * *$ & $-0.0003 * * *$ & $-0.0003 * * *$ & $-0.0003 * * *$ & $-0.0003 * * *$ & $-0.0003 * * *$ & $-0.0003 * * *$ & $-0.0003 * * *$ & $-0.0003 * * *$ \\
\hline vix*i & $0.0133 * * *$ & $0.0123 *$ & $0.0147 * * *$ & $0.0071 * *$ & $0.0149 * * *$ & $0.0134 * * *$ & $0.0098 * * *$ & $0.0175 * * *$ & 0.0091 & $0.0106^{*}$ & 0.0059 & $0.0092 *$ & 0.0060 \\
\hline
\end{tabular}


Table A3 CoVaR Estimations with External Effects of pessi and VIX - JEF, JP, MS and GS.

\begin{tabular}{|c|c|c|c|c|c|c|c|c|c|c|c|c|c|}
\hline $\mathbf{J}=\mathbf{J E F}$ & (40) & (41) & (42) & (43) & (44) & (45) & (46) & (47) & (48) & (49) & (50) & (51) & (52) \\
\hline $\mathbf{I}=$ & CITI & AIG & BOA & JP & MS & GS & RJF & SF & WF & BRK & LEH & MLC & BSC \\
\hline institution i & $\mathrm{i}-0.1443$ & $-0.3318^{*}$ & $-0.4922 * *$ & -0.2198 & 0.0576 & 0.1849 & -0.1407 & $-0.5586^{* *}$ & -0.1108 & -0.3827 & 0.1872 & -0.1053 & -0.2454 \\
\hline pessi & -0.0613 & -0.0786 & $-0.1057^{*}$ & -0.0500 & -0.0653 & -0.0201 & -0.0564 & -0.0698 & -0.0977 & -0.0475 & -0.0156 & -0.0713 & -0.0791 \\
\hline vix & -0.0000 & 0.0000 & 0.0000 & 0.0001 & -0.0000 & $-0.0003 * * *$ & 0.0001 & -0.0001 & -0.0001 & $-0.0004 * * *$ & $-0.0002 *$ & 0.0001 & -0.0001 \\
\hline pessi*i & 6.9107 & $8.9154 * * *$ & 3.3622 & 1.6655 & -2.0956 & 1.1815 & 7.0066 & 7.6723 & 8.1625 & 1.5179 & 6.3353 & 3.3084 & 5.2856 \\
\hline vix*i & 0.0150 & $0.0198 * *$ & $0.0292 * * *$ & $0.0195 * *$ & 0.0120 & -0.0013 & $0.0159 *$ & $0.0267 *$ & 0.0123 & 0.0222 & 0.0023 & 0.0160 & 0.0208 \\
\hline $\mathbf{J}=\mathbf{J P}$ & (53) & (54) & (55) & (56) & (57) & (58) & (59) & (60) & (61) & (62) & (63) & (64) & (65) \\
\hline $\mathbf{I}=$ & CITI & AIG & BOA & JEF & MS & GS & RJF & SF & WF & BRK & LEH & MLC & BSC \\
\hline institution i & i 0.0329 & $-0.2042 *$ & $0.4768 * * *$ & $-0.4194 * * *$ & 0.0647 & -0.0713 & -0.0996 & $-0.2466^{*}$ & 0.2001 & $-0.7929 * *$ & 0.0714 & 0.2049 & 0.0402 \\
\hline pessi & -0.0103 & -0.0159 & -0.0209 & -0.0470 & -0.0239 & 0.0290 & -0.0602 & -0.0461 & -0.0389 & $-0.1013 * *$ & -0.0051 & 0.0065 & -0.0130 \\
\hline vix & $-0.0003 * * *$ & $-0.0005 * * *$ & $-0.0004 * * *$ & $-0.0005 * * *$ & $-0.0003 * * *$ & $-0.0007 * * *$ & $-0.0004 * * *$ & $-0.0006 * * *$ & $-0.0005 * * *$ & $-0.0009 * * *$ & $-0.0006 * * *$ & $-0.0004 * * *$ & $-0.0004 * * *$ \\
\hline pessi*i & 2.1051 & $5.8561 * * *$ & $8.0180 *$ & $8.2961 * * *$ & 3.0432 & 4.3697 & $10.7343 * *$ & 5.9103 & $9.2365^{*}$ & 8.9647 & 5.7935 & $9.4116^{*}$ & 5.5126 \\
\hline vix*i & $0.0231 * * *$ & $0.0334 * * *$ & 0.0054 & $0.0272 * * *$ & $0.0158 * *$ & $0.0102 *$ & $0.0152 * *$ & $0.0155^{* *}$ & $0.0144 *$ & $0.0418 * * *$ & 0.0107 & 0.0063 & 0.0168 \\
\hline $\mathbf{J}=\mathbf{M S}$ & (66) & (67) & (68) & (69) & (70) & (71) & (72) & (73) & (74) & (75) & (76) & (77) & (78) \\
\hline $\mathbf{I}=$ & CITI & AIG & BOA & JEF & JP & GS & RJF & SF & WF & BRK & LEH & MLC & BSC \\
\hline institution $\mathrm{i}$ & i 0.1023 & 0.0088 & 0.0582 & -0.2801 & 0.3417 & $0.3450 * * *$ & -0.1789 & -0.2248 & -0.0535 & -0.3094 & 0.2290 & 0.1775 & -0.1194 \\
\hline pessi & 0.0222 & 0.0113 & -0.0119 & -0.0643 & 0.0057 & -0.0083 & -0.0409 & -0.1010 & -0.0521 & -0.0444 & -0.0154 & -0.0271 & 0.0141 \\
\hline vix & $-0.0004 * * *$ & $-0.0006^{* * *}$ & $-0.0005^{* * *}$ & $-0.0006 * * *$ & $-0.0004 * * *$ & $-0.0004 * * *$ & $-0.0004 * * *$ & $-0.0007 * * *$ & $-0.0006 * * *$ & $-0.0009 * * *$ & $-0.0003 * * *$ & $-0.0003 * * *$ & $-0.0003 * * *$ \\
\hline pessi*i & $12.7913 *$ & $11.9073 * * *$ & ' $13.7794 *$ & $11.8682 * * *$ & $11.9712 * * *$ & $4.7872 *$ & $13.3785^{*}$ & 7.1840 & $12.7849 *$ & $18.1151^{*}$ & $11.9564 * *$ & 3.9621 & $11.5965^{* *}$ \\
\hline vix*i & $0.0182 * *$ & $0.0206 * * *$ & $0.0192 * * *$ & $0.0196 * * *$ & 0.0055 & -0.0009 & $0.0264 * * *$ & $0.0173 *$ & $0.0246 * *$ & 0.0130 & $0.0091 *$ & $0.0208 * * *$ & $0.0289 * *$ \\
\hline $\mathbf{J}=\mathbf{G S}$ & (79) & (80) & (81) & (82) & (83) & (84) & (85) & (86) & (87) & (88) & (89) & (90) & (91) \\
\hline $\mathbf{I}=$ & CITI & AIG & BOA & JEF & $\mathbf{J P}$ & MS & RJF & SF & WF & BRK & LEH & MLC & BSC \\
\hline institution $\mathrm{i}$ & i $1.3871 * * *$ & -0.3924 & 0.1097 & $0.6469^{*}$ & $1.0707 * * *$ & $0.5646^{*}$ & 0.5231 & -0.1074 & 0.7105 & -0.3454 & $1.1797 * *$ & $1.0423 * * *$ & -0.0515 \\
\hline pessi & 0.1167 & 0.0500 & 0.0274 & 0.0933 & 0.1485 & 0.0096 & -0.0288 & -0.0226 & 0.0521 & -0.0462 & 0.0685 & 0.0846 & 0.0213 \\
\hline vix & $-0.0011 * * *$ & $-0.0012 * * *$ & $-0.0014 * * *$ & $-0.0014 * * *$ & $-0.0013 * * *$ & $-0.0007 * * *$ & $-0.0010 * * *$ & $-0.0016 * * *$ & $-0.0014 * * *$ & $-0.0013 * * *$ & $-0.0010 * * *$ & $-0.0009 * * *$ & $-0.0010 * * *$ \\
\hline pessi*i & $21.1651 *$ & 19.1183 & $30.8657^{*}$ & 11.2210 & $25.4354 * *$ & -1.8571 & 0.6622 & -6.4814 & 18.3137 & 28.8088 & 10.1007 & 8.0389 & 7.8647 \\
\hline $\mathbf{v i x}^{*} \mathbf{i}$ & -0.0068 & $0.0547 * *$ & $0.0408 * *$ & -0.0062 & -0.0075 & $0.0457 * * *$ & $0.0308 * *$ & 0.0323 & 0.0082 & 0.0229 & -0.0033 & $0.0210^{*}$ & $0.0592 * *$ \\
\hline
\end{tabular}


Table A3 Cont. CoVaR Estimations with External Effects of pessi and VIX - RJF, SF, WF and BRK.

\begin{tabular}{|c|c|c|c|c|c|c|c|c|c|c|c|c|c|}
\hline $\mathbf{J}=\mathbf{R J F}$ & (92) & (93) & (94) & (95) & (96) & (97) & (98) & (99) & (100) & (101) & (102) & (103) & (104) \\
\hline $\mathbf{I}=$ & CITI & AIG & BOA & JEF & JP & MS & GS & SF & WF & BRK & LEH & MLC & BSC \\
\hline institution i & $\mathrm{i}-0.0307$ & -0.0741 & -0.1514 & $-0.2676^{* *}$ & 0.0149 & 0.1799 & 0.0785 & $-0.5028 * *$ & -0.0810 & -0.1314 & 0.2389 & 0.2694 & 0.2245 \\
\hline pessi & $0.0801 *$ & 0.0531 & 0.0636 & 0.0566 & 0.0525 & 0.0636 & 0.0462 & 0.0352 & 0.0227 & 0.0118 & 0.0512 & 0.0377 & 0.0452 \\
\hline vix & $-0.0002 * * *$ & $-0.0003 * * *$ & $-0.0004 * * *$ & $-0.0003 * * *$ & $-0.0004 * * *$ & $-0.0003 * * *$ & $-0.0004 * * *$ & $-0.0005 * * *$ & $-0.0004 * * *$ & $-0.0006 * * *$ & $-0.0004 * * *$ & $-0.0002 * * *$ & $-0.0003 * * *$ \\
\hline pessi*i & 2.4580 & 3.7162 & $10.4125^{*}$ & -2.6469 & 2.0859 & 0.1888 & 1.6587 & 2.5052 & $9.3672 *$ & 1.2628 & $7.8362 * * *$ & -1.5454 & -1.4120 \\
\hline vix*i & $0.0209 * * *$ & $0.0174 * *$ & $0.0188 * * *$ & $0.0248 * * *$ & $0.0151 * * *$ & $0.0104 *$ & 0.0033 & $0.0301 * * *$ & 0.0131 & 0.0154 & 0.0012 & 0.0098 & 0.0127 \\
\hline $\mathbf{J}=\mathbf{S F}$ & (105) & (106) & (107) & (108) & (109) & (110) & (111) & (112) & (113) & (114) & (115) & (116) & (117) \\
\hline $\mathbf{I}=$ & CITI & AIG & BOA & JEF & JP & MS & GS & RJF & WF & BRK & LEH & MLC & BSC \\
\hline institution i & i 0.2773 & 0.1269 & 0.1429 & -0.0161 & 0.2789 & 0.1013 & $0.1800^{*}$ & -0.0642 & $0.2492 *$ & -0.1222 & 0.3256 & 0.3424 & 0.2403 \\
\hline pessi & 0.0162 & 0.0125 & 0.0067 & 0.0059 & 0.0284 & -0.0151 & 0.0712 & 0.0258 & 0.0407 & -0.0448 & -0.0185 & 0.0047 & -0.0018 \\
\hline vix & 0.0001 & 0.0001 & 0.0001 & 0.0001 & 0.0001 & 0.0000 & $0.0002 * *$ & -0.0000 & 0.0001 & 0.0002 & $0.0002 *$ & 0.0001 & 0.0000 \\
\hline pessi*i & 3.2604 & 1.1593 & 13.5602 & $10.2025 * * *$ & $4.3009 *$ & 2.8164 & -0.7196 & 5.1439 & $11.2800 *$ & 3.6943 & 5.1128 & 1.3459 & 9.3646 \\
\hline vix*i & -0.0041 & 0.0003 & -0.0055 & -0.0004 & -0.0058 & 0.0014 & -0.0039 & 0.0093 & -0.0057 & 0.0093 & -0.0096 & -0.0056 & -0.0063 \\
\hline $\mathbf{J}=\mathbf{W F}$ & (118) & (119) & (120) & (121) & (122) & (123) & (124) & (125) & (126) & (127) & (128) & (129) & (130) \\
\hline $\mathbf{I}=$ & CITI & AIG & BOA & JEF & JP & MS & GS & RJF & SF & BRK & LEH & MLC & BSC \\
\hline institution $\mathrm{i}$ & i 0.1424 & $0.1670 * *$ & $0.4301 * * *$ & $-0.1591 *$ & $0.4158 * * *$ & 0.0081 & 0.0266 & -0.0253 & $-0.2514^{*}$ & 0.2952 & 0.0933 & 0.0510 & 0.0800 \\
\hline pessi & 0.0374 & 0.0218 & $0.0570 *$ & 0.0384 & 0.0446 & $0.0767 *$ & 0.0432 & 0.0211 & 0.0072 & -0.0027 & 0.0393 & 0.0514 & 0.0444 \\
\hline vix & $-0.0001 *$ & $-0.0001 * *$ & $-0.0001 * * *$ & $-0.0002 * * *$ & $-0.0001 * *$ & $-0.0001 * *$ & $-0.0005 * * *$ & $-0.0002 * * *$ & $-0.0002 * * *$ & $-0.0004 * * *$ & $-0.0003 * * *$ & $-0.0001 * *$ & $-0.0002 * *$ \\
\hline pessi*i & 1.9631 & -0.8562 & 2.8415 & $5.9844 * * *$ & 0.0892 & 0.8331 & $3.0429 *$ & $5.5113^{*}$ & 2.0428 & 1.1376 & $4.8383^{*}$ & 2.5103 & 5.2224 \\
\hline vix*i & $0.0077 * *$ & $0.0113 * * *$ & 0.0015 & $0.0107 * * *$ & -0.0005 & $0.0104 *$ & 0.0006 & $0.0072 *$ & $0.0153 * *$ & -0.0061 & 0.0033 & $0.0077 *$ & 0.0044 \\
\hline $\mathbf{J}=\mathbf{B R K}$ & (131) & (132) & (133) & (134) & (135) & (136) & (137) & (138) & (139) & (140) & (141) & (142) & (143) \\
\hline $\mathbf{I}=$ & CITI & AIG & BOA & JEF & JP & MS & GS & RJF & SF & WF & LEH & MLC & BSC \\
\hline institution $\mathrm{i}$ & $\mathrm{i}-0.1722$ & -0.1602 & $-0.2656 * * *$ & $-0.1568 * *$ & $-0.3260 * *$ & $-0.2382 * *$ & $-0.2027 * *$ & $-0.2885 * *$ & -0.1556 & -0.1282 & -0.0403 & -0.1458 & -0.0952 \\
\hline pessi & 0.0084 & 0.0191 & 0.0144 & 0.0291 & 0.0192 & 0.0126 & 0.0250 & 0.0196 & -0.0080 & -0.0098 & 0.0230 & 0.0480 & 0.0322 \\
\hline vix & $-0.0002 * * *$ & $-0.0003 * * *$ & $-0.0002 * * *$ & $-0.0003 * * *$ & $-0.0003 * * *$ & $-0.0002 * * *$ & $-0.0004 * * *$ & $-0.0003 * * *$ & $-0.0003 * * *$ & $-0.0003 * * *$ & $-0.0003 * * *$ & $-0.0003 * * *$ & $-0.0003 * * *$ \\
\hline pessi*i & 2.8732 & 1.9422 & 4.8032 & $3.9043 * *$ & $2.6444^{*}$ & 2.1780 & 2.0632 & 1.5838 & 0.5042 & -8.3914 & 1.3839 & 1.2830 & 2.7180 \\
\hline $\mathbf{v i x}^{*} \mathbf{i}$ & $0.0113 * *$ & 0.0107 & $0.0125 * * *$ & $0.0062 *$ & $0.0139 * * *$ & $0.0123^{* *}$ & $0.0086 * *$ & $0.0168 * * *$ & 0.0094 & $0.0149 * *$ & 0.0052 & 0.0091 & 0.0060 \\
\hline
\end{tabular}


Table A3 Cont. CoVaR Estimations with External Effects of pessi and VIX - LEH, MLC and BSC.

\begin{tabular}{|c|c|c|c|c|c|c|c|c|c|c|c|c|c|}
\hline $\mathbf{J}=\mathbf{L E H}$ & (144) & (145) & (146) & (147) & (148) & (149) & (150) & (151) & (152) & (153) & (154) & (155) & (156) \\
\hline $\mathbf{I}=$ & CITI & AIG & BOA & JEF & $\mathbf{J P}$ & MS & GS & RJF & SF & WF & BRK & MLC & BSC \\
\hline institution $\mathrm{i}$ & $\mathrm{i}-0.0789$ & $-0.3487 * * *$ & 0.0603 & $-0.3671 * * *$ & 0.2644 & 0.0485 & 0.1642 & -0.0652 & -0.2048 & 0.0767 & -0.2515 & 0.0159 & 0.0187 \\
\hline pessi & 0.0316 & 0.0219 & -0.0033 & -0.0218 & 0.0194 & 0.0162 & 0.0245 & -0.0340 & -0.0193 & -0.0085 & -0.0287 & 0.0483 & 0.0477 \\
\hline vix & $-0.0005 * * *$ & $-0.0006 * * *$ & $-0.0005 * * *$ & $-0.0005 * * *$ & $-0.0005 * * *$ & $-0.0003 * * *$ & $-0.0004 * * *$ & $-0.0005 * * *$ & $-0.0007 * * *$ & $-0.0006^{* * *}$ & $-0.0008 * * *$ & $-0.0004 * * *$ & $-0.0003 * * *$ \\
\hline pessi*i & 5.2664 & $15.1895 * * *$ & * 6.9341 & $7.4937 * * *$ & $5.1142 * * *$ & $5.0181 *$ & $4.5408^{*}$ & 5.5401 & 2.4175 & $13.0560 *$ & 11.2340 & 4.5802 & 6.8583 \\
\hline vix*i & $0.0288 * * *$ & $0.0292 * * *$ & $0.0225 * * *$ & $0.0268 * * *$ & 0.0109 & $0.0235 * * *$ & 0.0047 & $0.0270 * * *$ & $0.0201 * *$ & 0.0135 & 0.0193 & $0.0276 * * *$ & $0.0294 * * *$ \\
\hline $\mathbf{J}=\mathbf{M L C}$ & (157) & (158) & (159) & (160) & (161) & (162) & (163) & (164) & (165) & (166) & (167) & (168) & (169) \\
\hline $\mathbf{I}=$ & CITI & AIG & BOA & JEF & $\mathbf{J P}$ & MS & GS & RJF & SF & WF & BRK & LEH & BSC \\
\hline institution i & i $0.2984 *$ & 0.1142 & $0.4080 * * *$ & $-0.2026^{*}$ & $0.4244^{*}$ & $0.2511^{*}$ & $0.2015^{*}$ & -0.0653 & -0.0884 & -0.0054 & -0.2681 & $0.3649 * *$ & 0.1610 \\
\hline pessi & 0.0076 & 0.0159 & 0.0434 & -0.0293 & 0.0307 & -0.0024 & 0.0155 & -0.0359 & -0.0410 & -0.0580 & -0.0759 & 0.0440 & 0.0081 \\
\hline vix & $-0.0002 * * *$ & $-0.0004 * * *$ & $-0.0003 * * *$ & $-0.0003 * * *$ & $-0.0002 * * *$ & -0.0001 & $-0.0004 * * *$ & $-0.0003 * * *$ & $-0.0005 * * *$ & $-0.0004 * * *$ & $-0.0006 * * *$ & $-0.0002 * * *$ & $-0.0002 * * *$ \\
\hline pessi*i & 3.6870 & $9.4357 * * *$ & $14.6739 * *$ & $14.3019 * * *$ & $8.8251 * * *$ & 2.1939 & $6.0775 * *$ & $9.7351 *$ & 6.9303 & $13.5781 * *$ & $16.6466^{*}$ & $7.5131^{*}$ & $7.1526^{*}$ \\
\hline vix*i & $0.0132 *$ & $0.0156^{* * *}$ & 0.0016 & $0.0126^{* * *}$ & 0.0005 & $0.0146 * * *$ & 0.0003 & $0.0177 * * *$ & 0.0084 & $0.0203^{*}$ & 0.0120 & 0.0031 & $0.0182 * * *$ \\
\hline $\mathbf{J}=\mathbf{B S C}$ & (170) & (171) & (172) & (173) & (174) & (175) & (176) & (177) & (178) & (179) & (180) & (181) & (182) \\
\hline$I=$ & CITI & AIG & BOA & JEF & JP & MS & GS & RJF & SF & WF & BRK & LEH & MLC \\
\hline institution i & 0.0831 & $-0.1761 *$ & 0.1722 & $-0.2251 *$ & $0.2856^{*}$ & $0.2990 * *$ & $0.3784 * * *$ & -0.0395 & -0.2073 & -0.0362 & -0.0257 & $0.3503 * *$ & $0.3988 * *$ \\
\hline pessi & 0.0015 & 0.0062 & 0.0092 & -0.0193 & 0.0129 & 0.0105 & -0.0007 & 0.0112 & -0.0512 & -0.0222 & -0.0216 & 0.0043 & 0.0016 \\
\hline vix & $-0.0001 * *$ & $-0.0003 * * *$ & $-0.0002 * *$ & $-0.0003 * * *$ & $-0.0002 * * *$ & -0.0001 & $-0.0003 * * *$ & $-0.0001 *$ & $-0.0003 * * *$ & $-0.0003 * * *$ & $-0.0005 * * *$ & -0.0001 & -0.0000 \\
\hline pessi*i & 5.1558 & $11.9321 * * *$ & 6.9985 & $7.5622 * * *$ & $4.7456 * *$ & 0.4904 & 5.1055 & 5.6258 & 0.4986 & $10.6795 * *$ & 11.0586 & 2.7711 & 2.0959 \\
\hline vix*i & $0.0157 *$ & $0.0240 * * *$ & $0.0134 * *$ & $0.0181 * * *$ & 0.0050 & 0.0095 & $-0.0081^{*}$ & $0.0209 * * *$ & $0.0197 *$ & $0.0211 * *$ & 0.0091 & 0.0055 & 0.0085 \\
\hline
\end{tabular}




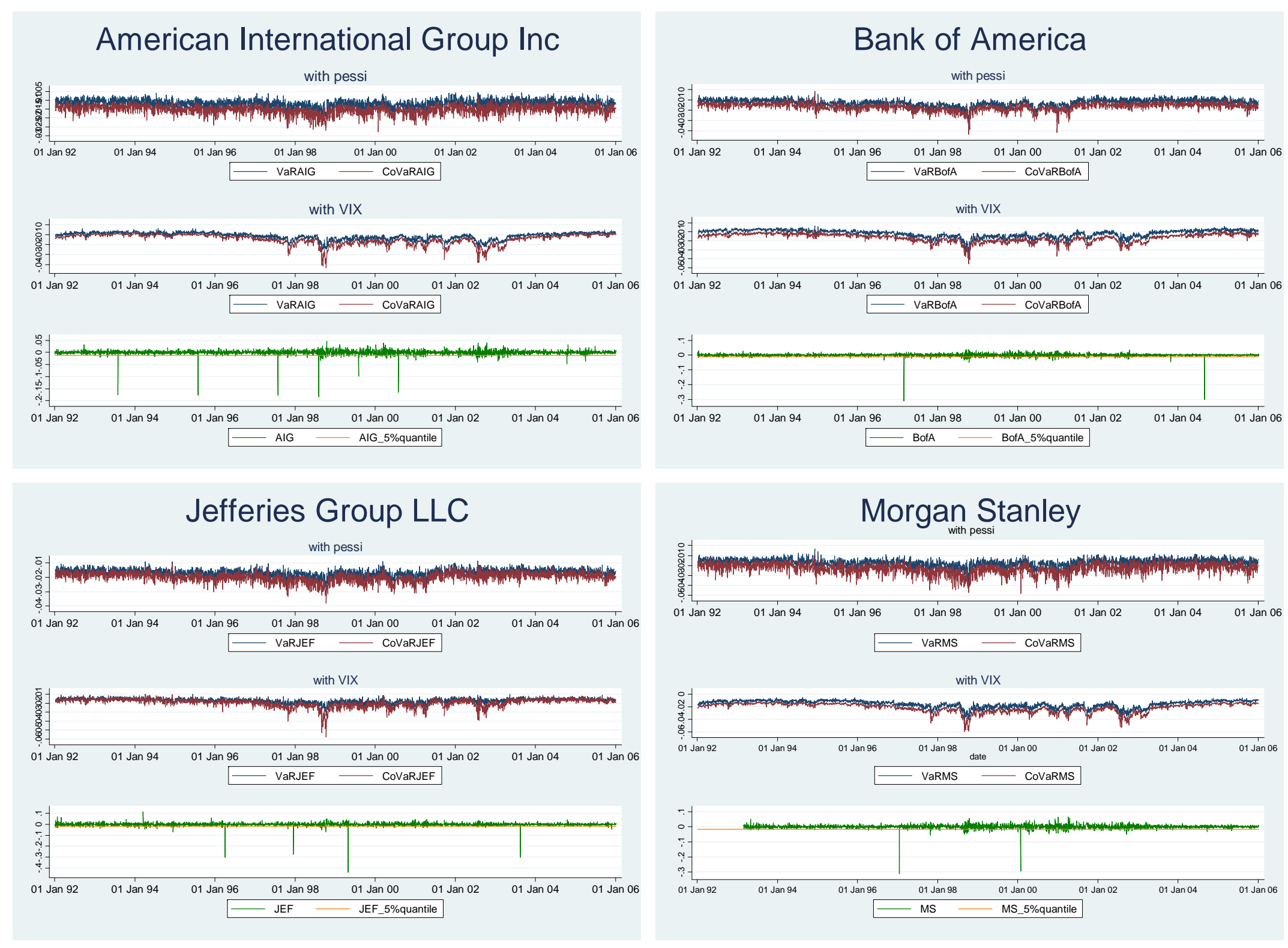



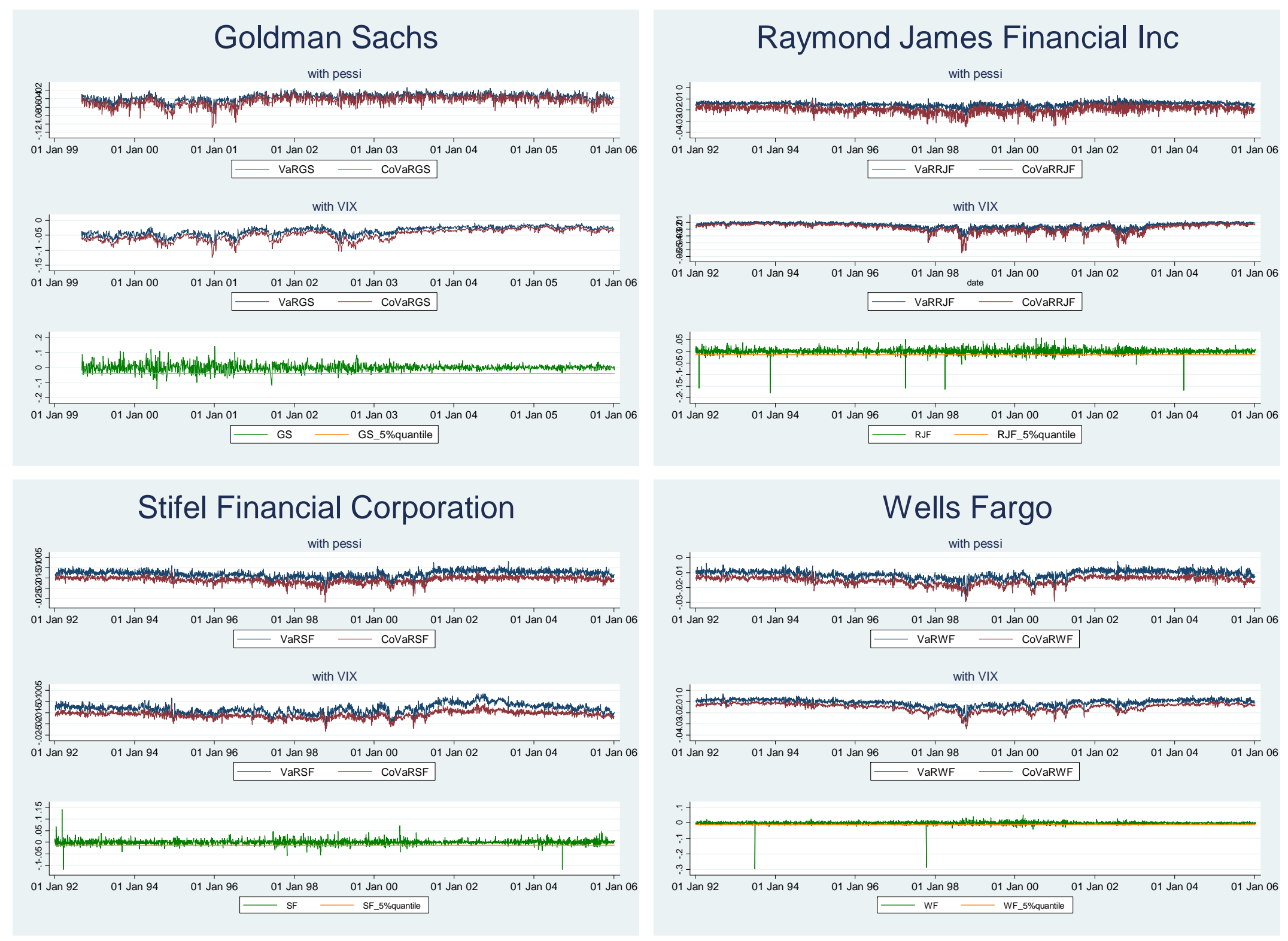

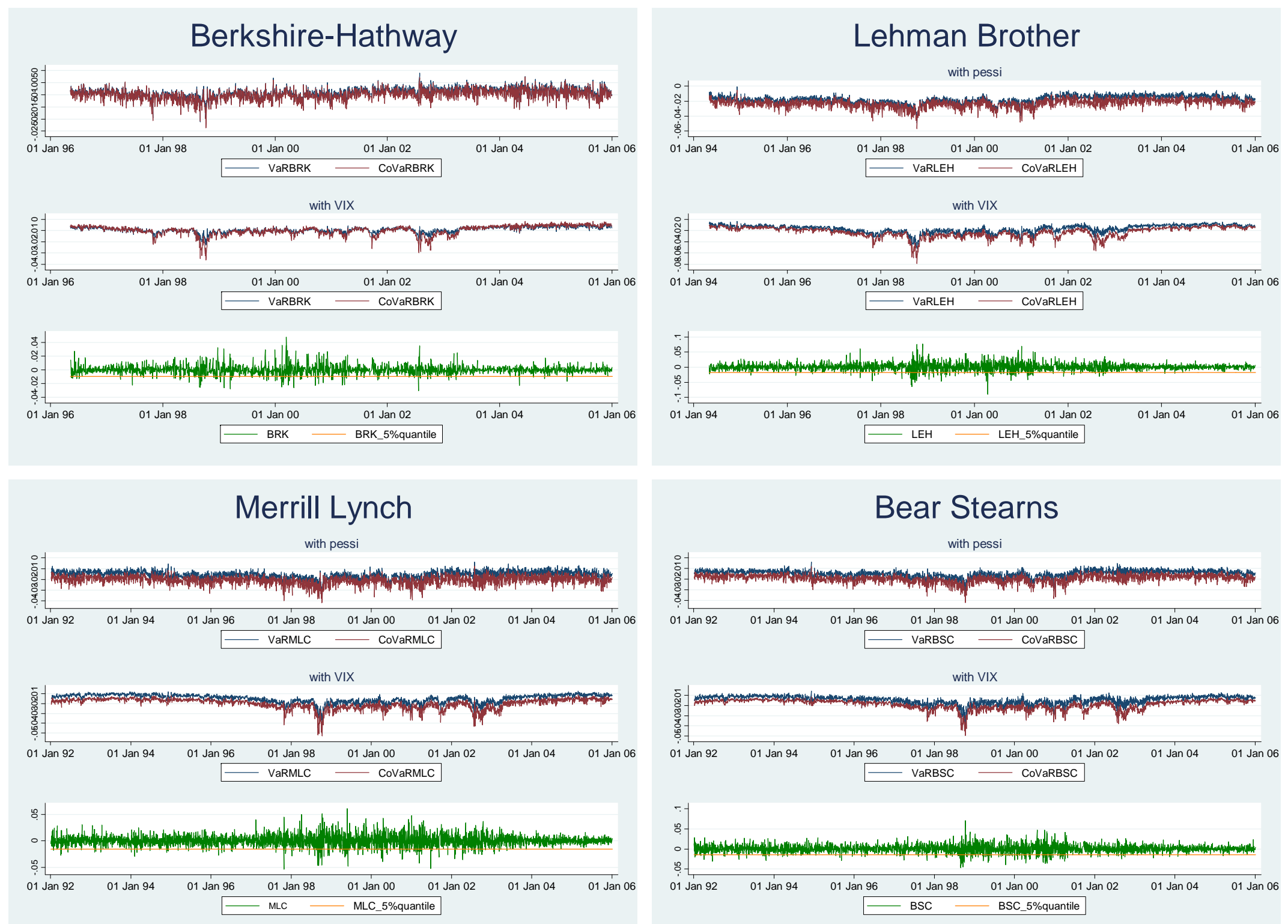

Figure A4 Daily returns 0.05 quantile predictions with pessi in row (1) and VIX in row (2) for the 14 financial institutions. 
Jefferies Group LLC

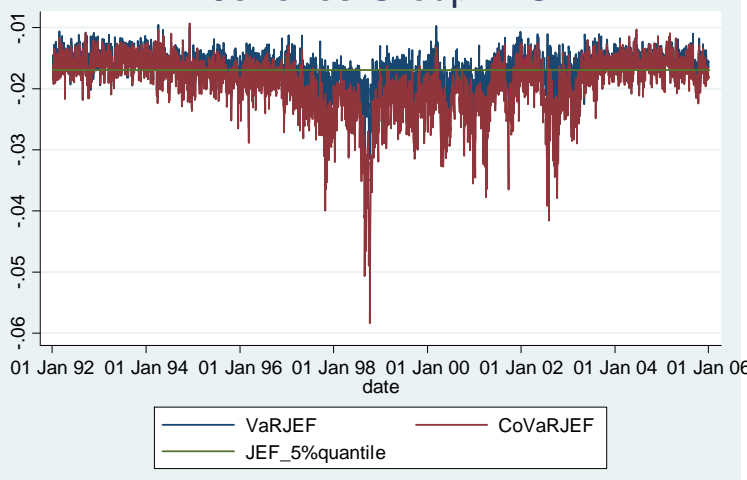

\section{Goldman Sachs}

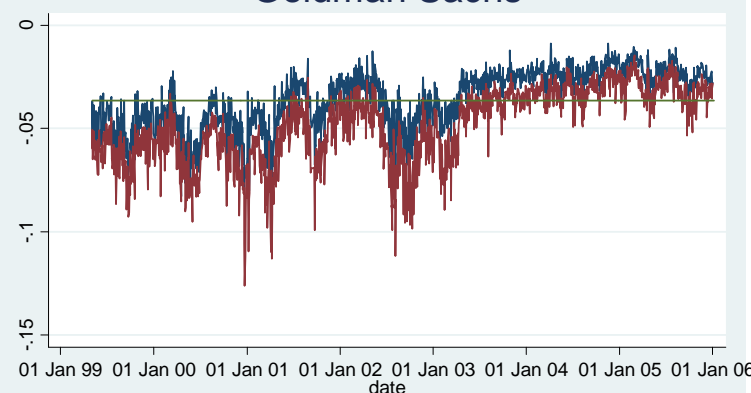

01 Jan 9901 Jan 0001 Jan 0101 Jan 0201 Jan 0301 Jan 0401 Jan 0501 Jan 06
JPMorgan Chase \& Co

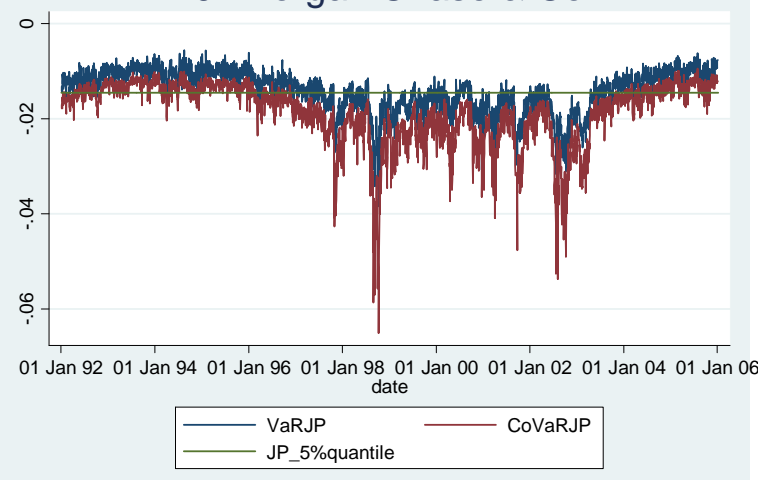

Raymond James Financial Inc

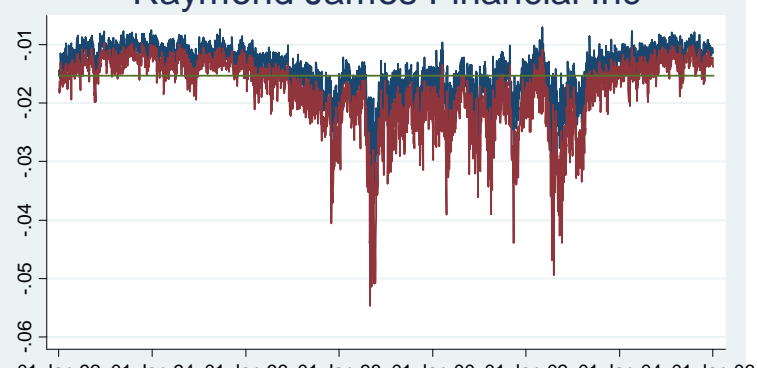

01 Jan 9201 Jan 9401 Jan 9601 Jan 98 date Jan 0001 Jan 0201 Jan 0401 Jan 06
Morgan Stanley

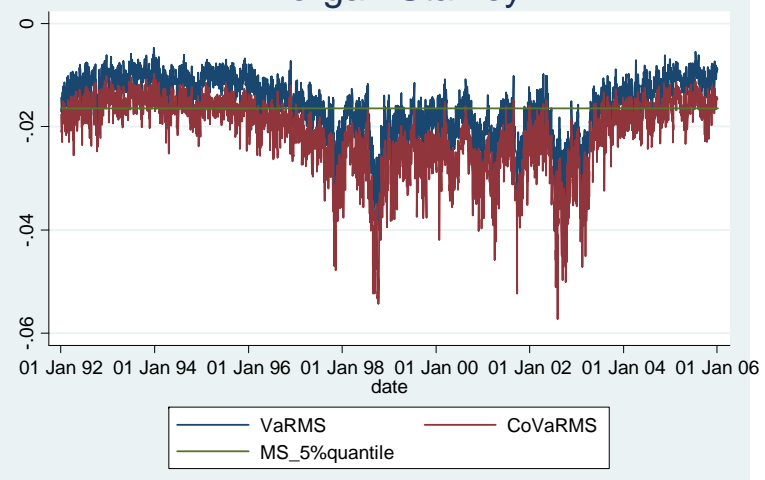

Stifel Financial Corporation

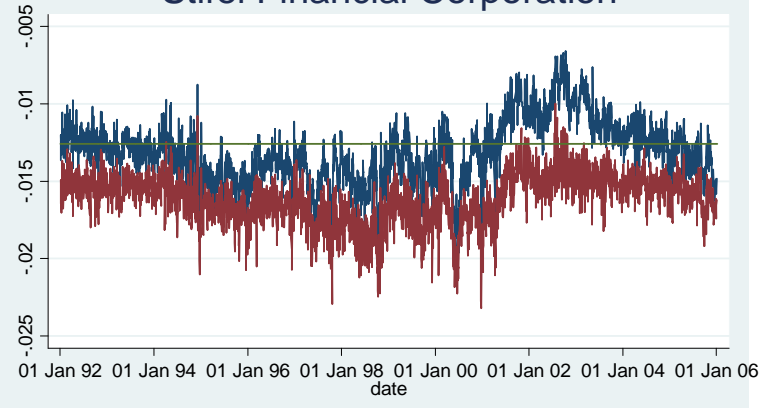



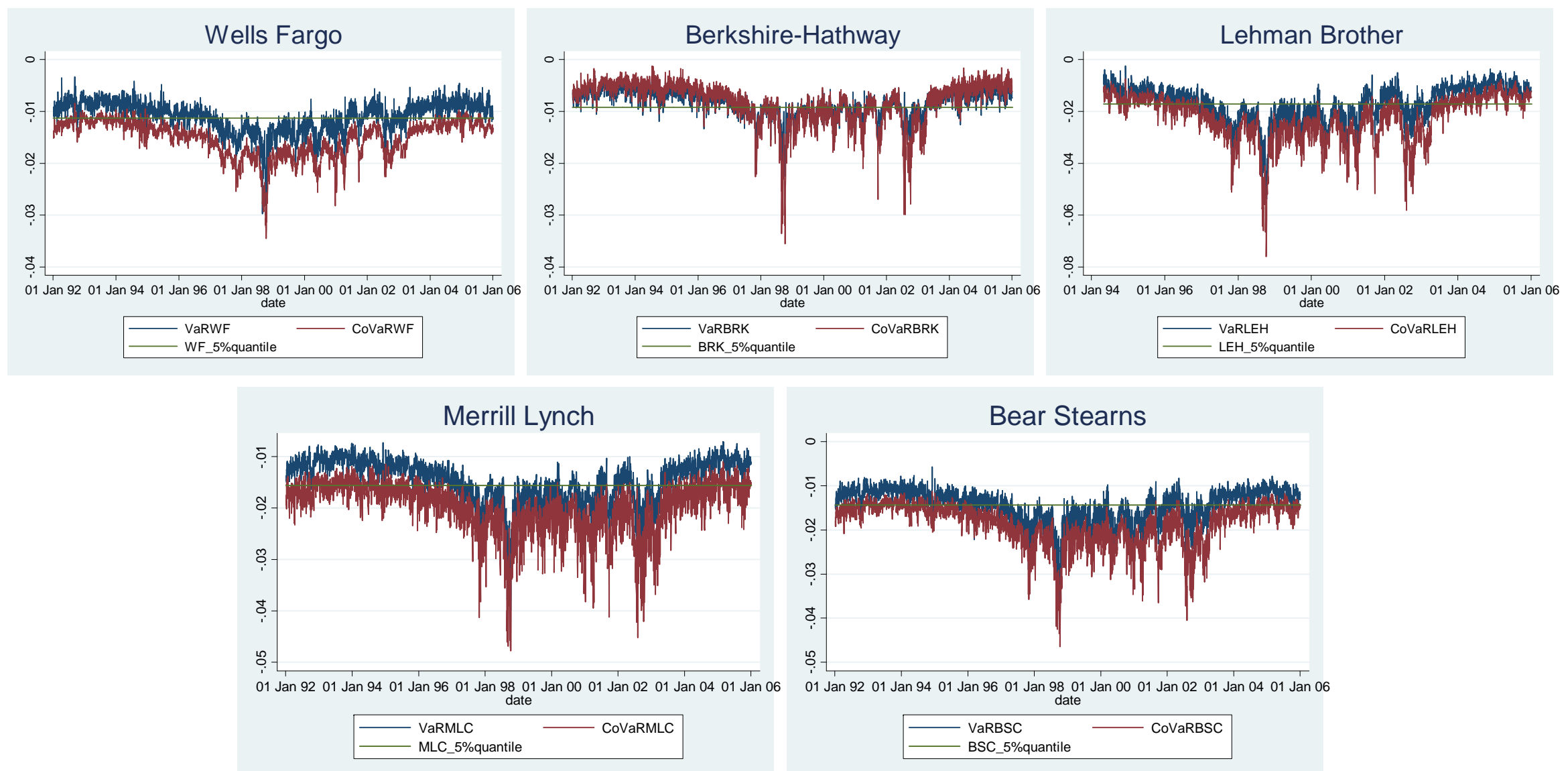

Figure A5 Daily returns 0.05 quantile predictions with pessi and VIX for the 14 financial institutions. 
Table A6: VIX Versus Consumer pessimism - In-Sample Forecasts Performance Squared difference between the mean of CoVaR estimate and the actual 5\% quantile return. Ranked by \% deviation between consumer pessimism and VIX discrepancy, column 3

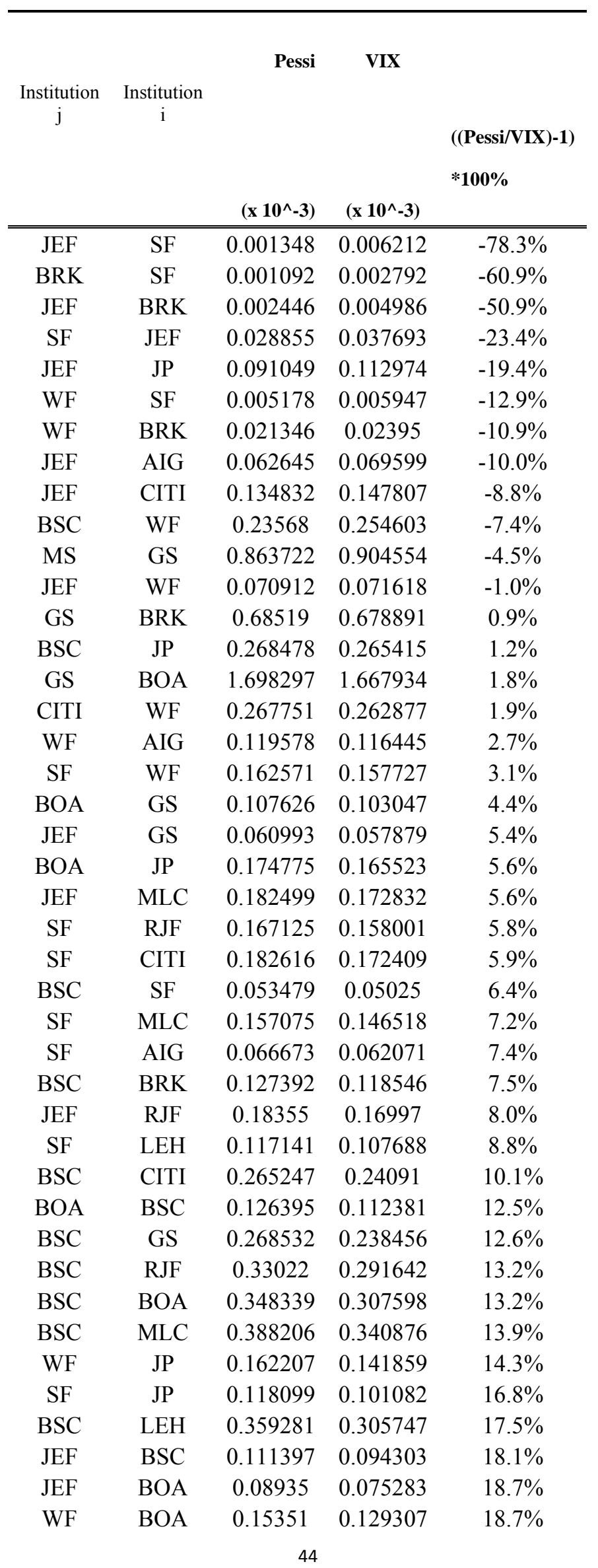




\begin{tabular}{|c|c|c|c|c|}
\hline BSC & JEF & 0.087775 & 0.07388 & $18.8 \%$ \\
\hline MLC & WF & 0.266664 & 0.224096 & $19.0 \%$ \\
\hline WF & LEH & 0.103668 & 0.087002 & $19.2 \%$ \\
\hline MS & JP & 0.464364 & 0.389533 & $19.2 \%$ \\
\hline MS & CITI & 0.436805 & 0.362972 & $20.3 \%$ \\
\hline WF & RJF & 0.058369 & 0.048426 & $20.5 \%$ \\
\hline WF & CITI & 0.101197 & 0.083329 & $21.4 \%$ \\
\hline BSC & AIG & 0.243456 & 0.198192 & $22.8 \%$ \\
\hline GS & CITI & 2.251574 & 1.816101 & $24.0 \%$ \\
\hline $\mathrm{JEF}$ & MS & 0.203619 & 0.162421 & $25.4 \%$ \\
\hline RJF & LEH & 0.264967 & 0.208018 & $27.4 \%$ \\
\hline GS & JP & 1.408588 & 1.094015 & $28.8 \%$ \\
\hline SF & $\mathrm{BOA}$ & 0.142208 & 0.1091 & $30.3 \%$ \\
\hline WF & MLC & 0.077473 & 0.059415 & $30.4 \%$ \\
\hline RJF & $\mathrm{BOA}$ & 0.148713 & 0.113748 & $30.7 \%$ \\
\hline MLC & $\mathrm{BOA}$ & 0.349194 & 0.263843 & $32.3 \%$ \\
\hline CITI & JP & 0.333534 & 0.251217 & $32.8 \%$ \\
\hline AIG & WF & 0.170349 & 0.128261 & $32.8 \%$ \\
\hline MLC & JP & 0.286852 & 0.21592 & $32.9 \%$ \\
\hline MLC & CITI & 0.391139 & 0.293382 & $33.3 \%$ \\
\hline CITI & MLC & 0.254317 & 0.189533 & $34.2 \%$ \\
\hline WF & MS & 0.111901 & 0.082511 & $35.6 \%$ \\
\hline RJF & JP & 0.14382 & 0.104889 & $37.1 \%$ \\
\hline CITI & $\mathrm{BOA}$ & 0.35542 & 0.25916 & $37.1 \%$ \\
\hline RJF & $\mathrm{BSC}$ & 0.281552 & 0.204206 & $37.9 \%$ \\
\hline MLC & MS & 0.391043 & 0.28355 & $37.9 \%$ \\
\hline $\mathrm{SF}$ & MS & 0.109636 & 0.079361 & $38.1 \%$ \\
\hline WF & $\mathrm{BSC}$ & 0.068159 & 0.049255 & $38.4 \%$ \\
\hline CITI & AIG & 0.356751 & 0.2563 & $39.2 \%$ \\
\hline BSC & MS & 0.329964 & 0.236579 & $39.5 \%$ \\
\hline MS & $\mathrm{BOA}$ & 0.476719 & 0.341785 & $39.5 \%$ \\
\hline MLC & $\mathrm{BSC}$ & 0.423276 & 0.303287 & $39.6 \%$ \\
\hline BOA & WF & 0.236673 & 0.169034 & $40.0 \%$ \\
\hline $\mathrm{BOA}$ & CITI & 0.14801 & 0.105643 & $40.1 \%$ \\
\hline LEH & BRK & 0.169178 & 0.120344 & $40.6 \%$ \\
\hline LEH & MLC & 0.529538 & 0.37617 & $40.8 \%$ \\
\hline MS & MLC & 0.500943 & 0.35345 & $41.7 \%$ \\
\hline SF & $\mathrm{BSC}$ & 0.223127 & 0.156753 & $42.3 \%$ \\
\hline JP & WF & 0.310759 & 0.217563 & $42.8 \%$ \\
\hline AIG & $\mathrm{BSC}$ & 0.11791 & 0.08253 & $42.9 \%$ \\
\hline $\mathrm{SF}$ & BRK & 0.052371 & 0.036378 & $44.0 \%$ \\
\hline MLC & AIG & 0.330738 & 0.229191 & $44.3 \%$ \\
\hline AIG & BRK & 0.201168 & 0.137827 & $46.0 \%$ \\
\hline MLC & LEH & 0.380993 & 0.259091 & $47.0 \%$ \\
\hline AIG & GS & 0.239133 & 0.160657 & $48.8 \%$ \\
\hline BOA & AIG & 0.202346 & 0.13547 & $49.4 \%$ \\
\hline AIG & MS & 0.149524 & 0.099577 & $50.2 \%$ \\
\hline MS & LEH & 0.577682 & 0.383825 & $50.5 \%$ \\
\hline CITI & LEH & 0.236735 & 0.156796 & $51.0 \%$ \\
\hline LEH & $\mathrm{BSC}$ & 0.501678 & 0.324237 & $54.7 \%$ \\
\hline MS & BSC & 0.539633 & 0.34499 & $56.4 \%$ \\
\hline
\end{tabular}




\begin{tabular}{|c|c|c|c|c|}
\hline JP & JEF & 0.067043 & 0.042832 & $56.5 \%$ \\
\hline CITI & $\mathrm{BSC}$ & 0.282512 & 0.180468 & $56.5 \%$ \\
\hline AIG & JP & 0.156646 & 0.099946 & $56.7 \%$ \\
\hline $\mathrm{RJF}$ & CITI & 0.218286 & 0.138976 & $57.1 \%$ \\
\hline BOA & MS & 0.126978 & 0.080536 & $57.7 \%$ \\
\hline JEF & LEH & 0.202382 & 0.127506 & $58.7 \%$ \\
\hline CITI & MS & 0.302157 & 0.190302 & $58.8 \%$ \\
\hline JP & CITI & 0.355735 & 0.223006 & $59.5 \%$ \\
\hline JP & $\mathrm{BOA}$ & 0.378491 & 0.23673 & $59.9 \%$ \\
\hline RJF & GS & 0.179721 & 0.110255 & $63.0 \%$ \\
\hline JP & MLC & 0.296283 & 0.178151 & $66.3 \%$ \\
\hline MLC & GS & 0.433302 & 0.259907 & $66.7 \%$ \\
\hline LEH & $\mathrm{BOA}$ & 0.413269 & 0.247399 & $67.0 \%$ \\
\hline JP & AIG & 0.315109 & 0.188461 & $67.2 \%$ \\
\hline JP & $\mathrm{BSC}$ & 0.343118 & 0.204938 & $67.4 \%$ \\
\hline CITI & RJF & 0.185184 & 0.110154 & $68.1 \%$ \\
\hline BOA & LEH & 0.168994 & 0.099637 & $69.6 \%$ \\
\hline MLC & RJF & 0.212559 & 0.124411 & $70.9 \%$ \\
\hline AIG & RJF & 0.093703 & 0.054727 & $71.2 \%$ \\
\hline BOA & MLC & 0.15812 & 0.092123 & $71.6 \%$ \\
\hline LEH & GS & 0.478279 & 0.277932 & $72.1 \%$ \\
\hline GS & RJF & 2.550447 & 1.472852 & $73.2 \%$ \\
\hline MS & BRK & 0.264367 & 0.151767 & $74.2 \%$ \\
\hline AIG & LEH & 0.16861 & 0.0964 & $74.9 \%$ \\
\hline LEH & CITI & 0.363672 & 0.206981 & $75.7 \%$ \\
\hline RJF & MS & 0.200932 & 0.114333 & $75.7 \%$ \\
\hline MS & AIG & 0.459558 & 0.259745 & $76.9 \%$ \\
\hline MS & WF & 0.499094 & 0.281082 & $77.6 \%$ \\
\hline $\mathrm{RJF}$ & MLC & 0.286472 & 0.160654 & $78.3 \%$ \\
\hline AIG & BOA & 0.174625 & 0.097744 & $78.7 \%$ \\
\hline AIG & CITI & 0.154943 & 0.085242 & $81.8 \%$ \\
\hline GS & MLC & 2.658803 & 1.455671 & $82.7 \%$ \\
\hline JP & GS & 0.646734 & 0.353902 & $82.7 \%$ \\
\hline LEH & MS & 0.577596 & 0.314995 & $83.4 \%$ \\
\hline JP & BRK & 0.220221 & 0.114724 & $92.0 \%$ \\
\hline BOA & BRK & 0.102546 & 0.053257 & $92.6 \%$ \\
\hline GS & MS & 1.99941 & 1.022503 & $95.5 \%$ \\
\hline AIG & MLC & 0.167654 & 0.085377 & $96.4 \%$ \\
\hline LEH & JP & 0.469054 & 0.238267 & $96.9 \%$ \\
\hline LEH & RJF & 0.398677 & 0.197823 & $101.5 \%$ \\
\hline GS & WF & 1.075598 & 0.532953 & $101.8 \%$ \\
\hline GS & LEH & 2.81106 & 1.386438 & $102.8 \%$ \\
\hline BOA & RJF & 0.076691 & 0.037485 & $104.6 \%$ \\
\hline CITI & GS & 0.216809 & 0.104545 & $107.4 \%$ \\
\hline JP & RJF & 0.181793 & 0.08624 & $110.8 \%$ \\
\hline BOA & JEF & 0.071241 & 0.033762 & $111.0 \%$ \\
\hline CITI & JEF & 0.111532 & 0.052152 & $113.9 \%$ \\
\hline GS & $\mathrm{BSC}$ & 2.244267 & 1.035857 & $116.7 \%$ \\
\hline JP & LEH & 0.387601 & 0.178715 & $116.9 \%$ \\
\hline MS & RJF & 0.47089 & 0.210418 & $123.8 \%$ \\
\hline RJF & WF & 0.140901 & 0.062355 & $126.0 \%$ \\
\hline
\end{tabular}




\begin{tabular}{|c|c|c|c|c|}
\hline MS & $\mathrm{SF}$ & 0.101603 & 0.044303 & $129.3 \%$ \\
\hline BRK & LEH & 0.030063 & 0.013024 & $130.8 \%$ \\
\hline AIG & JEF & 0.064461 & 0.027912 & $130.9 \%$ \\
\hline JP & MS & 0.377644 & 0.163366 & $131.2 \%$ \\
\hline MLC & JEF & 0.109566 & 0.047214 & $132.1 \%$ \\
\hline GS & AIG & 1.032199 & 0.439094 & $135.1 \%$ \\
\hline MLC & BRK & 0.098885 & 0.039477 & $150.5 \%$ \\
\hline WF & JEF & 0.022556 & 0.008955 & $151.9 \%$ \\
\hline RJF & AIG & 0.190069 & 0.073804 & $157.5 \%$ \\
\hline BRK & CITI & 0.030741 & 0.011867 & $159.1 \%$ \\
\hline RJF & BRK & 0.10615 & 0.038141 & $178.3 \%$ \\
\hline CITI & SF & 0.026407 & 0.00923 & $186.1 \%$ \\
\hline JP & SF & 0.012447 & 0.004314 & $188.6 \%$ \\
\hline GS & JEF & 1.500112 & 0.503509 & $197.9 \%$ \\
\hline MS & JEF & 0.265374 & 0.08788 & $202.0 \%$ \\
\hline CITI & BRK & 0.236172 & 0.075339 & $213.5 \%$ \\
\hline LEH & WF & 0.385154 & 0.122637 & $214.1 \%$ \\
\hline BRK & MLC & 0.012359 & 0.003935 & $214.1 \%$ \\
\hline RJF & JEF & 0.103375 & 0.031313 & $230.1 \%$ \\
\hline $\mathrm{BOA}$ & SF & 0.017565 & 0.004996 & $251.6 \%$ \\
\hline BRK & RJF & 0.014456 & 0.00388 & $272.6 \%$ \\
\hline LEH & JEF & 0.22054 & 0.054045 & $308.1 \%$ \\
\hline LEH & AIG & 0.328151 & 0.077585 & $323.0 \%$ \\
\hline WF & GS & 0.062842 & 0.014317 & $338.9 \%$ \\
\hline MLC & SF & 0.03069 & 0.005489 & $459.1 \%$ \\
\hline SF & GS & 0.05225 & 0.00853 & $512.6 \%$ \\
\hline GS & $\mathrm{SF}$ & 0.377937 & 0.057001 & $563.0 \%$ \\
\hline BRK & GS & 0.008146 & 0.001191 & $584.3 \%$ \\
\hline BRK & $\mathrm{BSC}$ & 0.016206 & 0.00226 & $617.0 \%$ \\
\hline AIG & $\mathrm{SF}$ & 0.032092 & 0.004021 & $698.1 \%$ \\
\hline BRK & AIG & 0.007167 & 0.000474 & $1411.7 \%$ \\
\hline RJF & $\mathrm{SF}$ & 0.05919 & 0.003486 & $1597.9 \%$ \\
\hline LEH & $\mathrm{SF}$ & 0.161751 & 0.00943 & $1615.2 \%$ \\
\hline BRK & BOA & 0.009276 & 0.000331 & $2704.9 \%$ \\
\hline BRK & MS & 0.013134 & 0.000426 & $2985.3 \%$ \\
\hline BRK & WF & 0.009633 & 0.000207 & $4553.7 \%$ \\
\hline BRK & JP & 0.005766 & $5.98 \mathrm{E}-07$ & $964180.9 \%$ \\
\hline \multirow[t]{4}{*}{ BRK } & JEF & 0.012444 & $4.43 \mathrm{E}-07$ & $2808816.5 \%$ \\
\hline & & & Positives & 170 \\
\hline & & & Negatives & 12 \\
\hline & & & Total & 182 \\
\hline
\end{tabular}


Table A7: VIX Versus Consumer pessimism - Out-of-Sample 2-Day Forecasts Performance Squared difference between the predicted mean of CoVaR estimate and the actual 2-Day 5\% quantile return - Estimation up to November 16, 2005; forecast for November 17 and 18, 2005 Ranked by \% deviation between consumer pessimism and VIX discrepancy, column 3

\begin{tabular}{|c|c|c|c|c|}
\hline Institution $\mathrm{j}$ & Institution i & $\begin{array}{r}\text { Pessi } \\
\left(\times 10^{\wedge}-3\right)\end{array}$ & $\begin{array}{c}\text { VIX } \\
\left(x 1^{\wedge}-3\right)\end{array}$ & $\begin{array}{c}\text { ((Pessi/VIX)-1) } \\
* 100 \%\end{array}$ \\
\hline SF & JEF & 1.942171 & 2.437922 & $-20.33 \%$ \\
\hline SF & WF & 2.352344 & 2.739969 & $-14.15 \%$ \\
\hline SF & AIG & 2.159423 & 2.405204 & $-10.22 \%$ \\
\hline SF & $\mathrm{JP}$ & 2.475478 & 2.491328 & $-0.64 \%$ \\
\hline SF & BRK & 2.261274 & 2.245394 & $0.71 \%$ \\
\hline SF & GS & 2.29275 & 2.264019 & $1.27 \%$ \\
\hline SF & BSC & 2.752075 & 2.702424 & $1.84 \%$ \\
\hline SF & MLC & 2.535226 & 2.484764 & $2.03 \%$ \\
\hline SF & RJF & 2.761573 & 2.630625 & $4.98 \%$ \\
\hline SF & LEH & 2.359133 & 2.246216 & $5.03 \%$ \\
\hline SF & BOA & 2.440557 & 2.307223 & $5.78 \%$ \\
\hline SF & CITI & 2.72266 & 2.542945 & $7.07 \%$ \\
\hline $\mathrm{SF}$ & MS & 2.464602 & 2.206785 & $11.68 \%$ \\
\hline WF & $\mathrm{SF}$ & 1.209807 & 1.044809 & $15.79 \%$ \\
\hline JEF & AIG & 3.338412 & 2.868381 & $16.39 \%$ \\
\hline JEF & CITI & 3.682307 & 3.129714 & $17.66 \%$ \\
\hline JEF & JP & 3.429453 & 2.914651 & $17.66 \%$ \\
\hline JEF & $\mathrm{BSC}$ & 3.449061 & 2.764018 & $24.78 \%$ \\
\hline JEF & MLC & 3.917805 & 3.115407 & $25.76 \%$ \\
\hline JEF & RJF & 4.118752 & 3.26246 & $26.25 \%$ \\
\hline JEF & $\mathrm{SF}$ & 2.743714 & 2.17014 & $26.43 \%$ \\
\hline JEF & WF & 3.223473 & 2.549242 & $26.45 \%$ \\
\hline WF & JEF & 1.326308 & 1.019821 & $30.05 \%$ \\
\hline JEF & BOA & 3.479617 & 2.664378 & $30.60 \%$ \\
\hline WF & BSC & 1.769753 & 1.349094 & $31.18 \%$ \\
\hline WF & CITI & 1.886441 & 1.40757 & $34.02 \%$ \\
\hline WF & AIG & 2.146627 & 1.593275 & $34.73 \%$ \\
\hline WF & RJF & 1.624222 & 1.202967 & $35.02 \%$ \\
\hline CITI & $\mathrm{BSC}$ & 3.601528 & 2.635827 & $36.64 \%$ \\
\hline CITI & WF & 3.550954 & 2.561837 & $38.61 \%$ \\
\hline $\mathrm{BSC}$ & WF & 1.719433 & 1.223378 & $40.55 \%$ \\
\hline RJF & BSC & 5.369456 & 3.79219 & $41.59 \%$ \\
\hline BSC & RJF & 2.029397 & 1.425937 & $42.32 \%$ \\
\hline WF & JP & 2.417924 & 1.672796 & $44.54 \%$ \\
\hline WF & MLC & 1.866618 & 1.290811 & $44.61 \%$ \\
\hline WF & MS & 1.914226 & 1.28611 & $48.84 \%$ \\
\hline RJF & CITI & 5.008324 & 3.347965 & $49.59 \%$ \\
\hline WF & BOA & 2.134768 & 1.420231 & $50.31 \%$ \\
\hline LEH & BSC & 6.28787 & 4.154412 & $51.35 \%$ \\
\hline MLC & $\mathrm{BSC}$ & 5.35346 & 3.511132 & $52.47 \%$ \\
\hline $\mathrm{RJF}$ & MLC & 5.341581 & 3.489589 & $53.07 \%$ \\
\hline CITI & MLC & 3.998764 & 2.611924 & $53.10 \%$ \\
\hline
\end{tabular}




\begin{tabular}{|c|c|c|c|c|}
\hline MS & $\mathrm{BSC}$ & 6.96885 & 4.516205 & $54.31 \%$ \\
\hline $\mathrm{BOA}$ & WF & 3.140622 & 2.033107 & $54.47 \%$ \\
\hline MLC & WF & 4.932084 & 3.161284 & $56.02 \%$ \\
\hline $\mathrm{RJF}$ & JP & 5.127772 & 3.283734 & $56.16 \%$ \\
\hline BSC & JEF & 1.412601 & 0.900307 & $56.90 \%$ \\
\hline MLC & JP & 5.526424 & 3.502794 & $57.77 \%$ \\
\hline BSC & MLC & 2.187609 & 1.382984 & $58.18 \%$ \\
\hline RJF & WF & 4.903589 & 3.096208 & $58.37 \%$ \\
\hline RJF & JEF & 4.744335 & 2.987588 & $58.80 \%$ \\
\hline JEF & MS & 3.939287 & 2.478377 & $58.95 \%$ \\
\hline MS & CITI & 6.560898 & 4.088221 & $60.48 \%$ \\
\hline BOA & $\mathrm{BSC}$ & 3.041599 & 1.895133 & $60.50 \%$ \\
\hline CITI & RJF & 3.528651 & 2.180423 & $61.83 \%$ \\
\hline CITI & JP & 4.323224 & 2.653184 & $62.94 \%$ \\
\hline AIG & WF & 2.255066 & 1.38219 & $63.15 \%$ \\
\hline MLC & CITI & 5.372175 & 3.252335 & $65.18 \%$ \\
\hline BSC & SF & 1.263006 & 0.764228 & $65.27 \%$ \\
\hline BSC & CITI & 1.951362 & 1.178994 & $65.51 \%$ \\
\hline CITI & JEF & 3.204092 & 1.933635 & $65.70 \%$ \\
\hline MLC & RJF & 4.669344 & 2.817482 & $65.73 \%$ \\
\hline LEH & MLC & 6.608833 & 3.96781 & $66.56 \%$ \\
\hline CITI & AIG & 4.325739 & 2.580052 & $67.66 \%$ \\
\hline $\mathrm{RJF}$ & MS & 5.00636 & 2.985415 & $67.69 \%$ \\
\hline RJF & SF & 4.492619 & 2.677917 & $67.77 \%$ \\
\hline MS & MLC & 6.88662 & 4.071109 & $69.16 \%$ \\
\hline MLC & JEF & 4.261969 & 2.518174 & $69.25 \%$ \\
\hline BOA & CITI & 3.052892 & 1.790913 & $70.47 \%$ \\
\hline CITI & BOA & 4.236309 & 2.475193 & $71.15 \%$ \\
\hline MLC & MS & 5.581189 & 3.259196 & $71.24 \%$ \\
\hline RJF & BOA & 5.305974 & 3.088313 & $71.81 \%$ \\
\hline BSC & JP & 2.144636 & 1.239833 & $72.98 \%$ \\
\hline CITI & SF & 2.491138 & 1.42718 & $74.55 \%$ \\
\hline BSC & $\mathrm{BOA}$ & 2.07402 & 1.181718 & $75.51 \%$ \\
\hline MLC & BOA & 5.287671 & 3.011216 & $75.60 \%$ \\
\hline MLC & AIG & 5.226555 & 2.971304 & $75.90 \%$ \\
\hline RJF & AIG & 5.238264 & 2.967131 & $76.54 \%$ \\
\hline MS & JP & 6.946926 & 3.918919 & $77.27 \%$ \\
\hline BOA & MS & 2.857921 & 1.606003 & $77.95 \%$ \\
\hline BOA & JP & 3.209478 & 1.798234 & $78.48 \%$ \\
\hline BOA & JEF & 2.638358 & 1.449512 & $82.02 \%$ \\
\hline CITI & LEH & 3.452426 & 1.855065 & $86.11 \%$ \\
\hline CITI & MS & 4.116371 & 2.211076 & $86.17 \%$ \\
\hline MLC & LEH & 5.197607 & 2.78556 & $86.59 \%$ \\
\hline JP & $\mathrm{BSC}$ & 4.255633 & 2.279116 & $86.72 \%$ \\
\hline MLC & SF & 3.784847 & 2.022245 & $87.16 \%$ \\
\hline BOA & RJF & 2.672751 & 1.422405 & $87.90 \%$ \\
\hline BSC & AIG & 1.874667 & 0.994305 & $88.54 \%$ \\
\hline AIG & $\mathrm{BSC}$ & 2.374555 & 1.258444 & $88.69 \%$ \\
\hline BOA & MLC & 3.143259 & 1.659789 & $89.38 \%$ \\
\hline RJF & LEH & 5.403325 & 2.852984 & $89.39 \%$ \\
\hline AIG & JEF & 1.907632 & 1.007076 & $89.42 \%$ \\
\hline
\end{tabular}




\begin{tabular}{|c|c|c|c|c|}
\hline BOA & AIG & 3.341969 & 1.760011 & $89.88 \%$ \\
\hline MS & RJF & 6.823609 & 3.577242 & $90.75 \%$ \\
\hline JEF & LEH & 3.545684 & 1.850303 & $91.63 \%$ \\
\hline JP & JEF & 3.145373 & 1.634583 & $92.43 \%$ \\
\hline AIG & RJF & 2.114039 & 1.09471 & $93.11 \%$ \\
\hline GS & CITI & 28.15998 & 14.5007 & $94.20 \%$ \\
\hline BSC & LEH & 1.772998 & 0.908252 & $95.21 \%$ \\
\hline MS & WF & 6.862239 & 3.501405 & $95.99 \%$ \\
\hline MS & LEH & 6.685837 & 3.401514 & $96.55 \%$ \\
\hline GS & RJF & 31.72663 & 16.08741 & $97.21 \%$ \\
\hline BOA & SF & 2.298774 & 1.158791 & $98.38 \%$ \\
\hline LEH & CITI & 5.809449 & 2.906126 & $99.90 \%$ \\
\hline MS & SF & 5.407621 & 2.693029 & $100.80 \%$ \\
\hline GS & WF & 25.59517 & 12.74187 & $100.87 \%$ \\
\hline JP & CITI & 4.297112 & 2.125471 & $102.17 \%$ \\
\hline LEH & RJF & 6.225182 & 3.071242 & $102.69 \%$ \\
\hline GS & $\mathrm{BSC}$ & 30.89066 & 15.13654 & $104.08 \%$ \\
\hline GS & JP & 28.37911 & 13.8869 & $104.36 \%$ \\
\hline LEH & MS & 6.77536 & 3.294801 & $105.64 \%$ \\
\hline MS & AIG & 6.924701 & 3.359109 & $106.15 \%$ \\
\hline MS & JEF & 6.373816 & 3.061018 & $108.23 \%$ \\
\hline $\mathrm{JP}$ & RJF & 3.734957 & 1.79169 & $108.46 \%$ \\
\hline AIG & MLC & 2.468744 & 1.181758 & $108.90 \%$ \\
\hline $\mathrm{JP}$ & WF & 3.957147 & 1.89385 & $108.95 \%$ \\
\hline JP & AIG & 4.425122 & 2.11459 & $109.27 \%$ \\
\hline RJF & GS & 5.722419 & 2.731988 & $109.46 \%$ \\
\hline JP & MLC & 4.074294 & 1.940848 & $109.92 \%$ \\
\hline MS & BOA & 7.594952 & 3.604424 & $110.71 \%$ \\
\hline AIG & SF & 1.657549 & 0.785626 & $110.98 \%$ \\
\hline WF & LEH & 1.804632 & 0.850286 & $112.24 \%$ \\
\hline GS & AIG & 26.64104 & 12.49895 & $113.15 \%$ \\
\hline AIG & CITI & 2.460526 & 1.151872 & $113.61 \%$ \\
\hline $\mathrm{BSC}$ & MS & 2.018141 & 0.943933 & $113.80 \%$ \\
\hline MS & GS & 8.163847 & 3.809699 & $114.29 \%$ \\
\hline GS & $\mathrm{SF}$ & 22.7627 & 10.55 & $115.76 \%$ \\
\hline AIG & MS & 2.332002 & 1.078957 & $116.13 \%$ \\
\hline LEH & JEF & 5.254715 & 2.425364 & $116.66 \%$ \\
\hline BRK & MLC & 0.739624 & 0.339753 & $117.69 \%$ \\
\hline GS & MLC & 33.66457 & 15.42563 & $118.24 \%$ \\
\hline LEH & $\mathrm{BOA}$ & 6.454493 & 2.944171 & $119.23 \%$ \\
\hline JP & SF & 2.938582 & 1.335202 & $120.09 \%$ \\
\hline BRK & RJF & 0.750436 & 0.340962 & $120.09 \%$ \\
\hline GS & MS & 31.46671 & 14.27371 & $120.45 \%$ \\
\hline GS & $\mathrm{BOA}$ & 31.18878 & 14.10693 & $121.09 \%$ \\
\hline GS & JEF & 28.0317 & 12.61509 & $122.21 \%$ \\
\hline $\mathrm{JEF}$ & BRK & 2.397102 & 1.076112 & $122.76 \%$ \\
\hline RJF & BRK & 4.710132 & 2.097832 & $124.52 \%$ \\
\hline AIG & JP & 2.523475 & 1.12176 & $124.96 \%$ \\
\hline BRK & JP & 0.636003 & 0.282649 & $125.02 \%$ \\
\hline LEH & JP & 6.439223 & 2.840384 & $126.70 \%$ \\
\hline GS & BRK & 23.10686 & 10.17514 & $127.09 \%$ \\
\hline
\end{tabular}




\begin{tabular}{|c|c|c|c|c|}
\hline BRK & SF & 0.581099 & 0.254116 & $128.67 \%$ \\
\hline AIG & $\mathrm{BOA}$ & 2.688913 & 1.174215 & $129.00 \%$ \\
\hline AIG & LEH & 2.476247 & 1.075899 & $130.16 \%$ \\
\hline BRK & $\mathrm{BOA}$ & 0.698814 & 0.301198 & $132.01 \%$ \\
\hline BRK & WF & 0.677333 & 0.291402 & $132.44 \%$ \\
\hline JEF & GS & 3.510898 & 1.504399 & $133.38 \%$ \\
\hline BRK & JEF & 0.728465 & 0.311729 & $133.69 \%$ \\
\hline LEH & WF & 5.464827 & 2.326141 & $134.93 \%$ \\
\hline LEH & SF & 5.086164 & 2.163997 & $135.04 \%$ \\
\hline BRK & LEH & 0.773021 & 0.328154 & $135.57 \%$ \\
\hline JP & BOA & 4.32927 & 1.827341 & $136.92 \%$ \\
\hline LEH & GS & 6.886521 & 2.896788 & $137.73 \%$ \\
\hline BRK & BSC & 0.776659 & 0.324579 & $139.28 \%$ \\
\hline WF & BRK & 1.272625 & 0.530105 & $140.07 \%$ \\
\hline BRK & AIG & 0.722566 & 0.298538 & $142.03 \%$ \\
\hline BOA & LEH & 2.860044 & 1.180462 & $142.28 \%$ \\
\hline BRK & CITI & 0.874161 & 0.350966 & $149.07 \%$ \\
\hline BOA & GS & 3.197381 & 1.270108 & $151.74 \%$ \\
\hline AIG & GS & 2.959318 & 1.159527 & $155.22 \%$ \\
\hline LEH & BRK & 4.611801 & 1.784134 & $158.49 \%$ \\
\hline BRK & MS & 0.705696 & 0.271661 & $159.77 \%$ \\
\hline MLC & GS & 6.351687 & 2.44041 & $160.27 \%$ \\
\hline GS & LEH & 30.69075 & 11.70576 & $162.19 \%$ \\
\hline AIG & BRK & 2.488509 & 0.92648 & $168.60 \%$ \\
\hline LEH & AIG & 6.105378 & 2.249433 & $171.42 \%$ \\
\hline JP & MS & 4.841676 & 1.782174 & $171.67 \%$ \\
\hline BSC & GS & 2.123255 & 0.735282 & $188.77 \%$ \\
\hline WF & GS & 1.964035 & 0.648868 & $202.69 \%$ \\
\hline BRK & GS & 0.775596 & 0.253102 & $206.44 \%$ \\
\hline CITI & GS & 3.775725 & 1.135736 & $232.45 \%$ \\
\hline MLC & BRK & 4.338983 & 1.298038 & $234.27 \%$ \\
\hline JP & LEH & 4.10638 & 1.218104 & $237.11 \%$ \\
\hline MS & BRK & 6.103475 & 1.80824 & $237.54 \%$ \\
\hline BOA & BRK & 2.674179 & 0.789614 & $238.67 \%$ \\
\hline BSC & BRK & 1.457221 & 0.331498 & $339.59 \%$ \\
\hline JP & BRK & 3.989927 & 0.855356 & $366.46 \%$ \\
\hline CITI & BRK & 3.455858 & 0.724744 & $376.84 \%$ \\
\hline \multirow[t]{4}{*}{ JP } & GS & 5.397227 & 1.077779 & $400.77 \%$ \\
\hline & & & Positives & 178 \\
\hline & & & Negatives & 4 \\
\hline & & & Total & 182 \\
\hline
\end{tabular}

